\title{
TCSG-132 Gemi Batığı Yapay Resifinin (Gökçeada, Kuzey Ege Denizi) Biyoçeşitliliği
}

\section{Deniz ACARLI ${ }^{1} \oplus$, Semih KALE ${ }^{2 *} \mathbb{D}$, Sinan KOCABAŞ $S^{3}$}

${ }^{1}$ Çanakkale Onsekiz Mart Üniversitesi, Gökçeada Uygulamalı Bilimler Yüksekokulu, Balıkçılık Teknolojisi Bölümü, Çanakkale, Türkiye

${ }^{2}$ Çanakkale Onsekiz Mart Üniversitesi, Deniz Bilimleri ve Teknolojisi Fakültesi, Su Ürünleri Avlama ve İşleme Teknolojisi Bölümü, Çanakkale, Türkiye

${ }^{3}$ Çanakkale Onsekiz Mart Üniversitesi, Fen Bilimleri Enstitüsü, Su Ürünleri Avlama ve İşleme Teknolojisi Bölümü, Çanakkale, Türkiye

*Sorumlu yazar: semihkale@comu.edu.tr

Geliş 19 Ocak 2020; Kabul 13 Ağustos 2020; Basım 01 Eylül 2020.

Alıntılama: Acarlı, D., Kale, S., \& Kocabaş, S. (2020). TCSG-132 Gemi batığı yapay resifinin (Gökçeada, Kuzey Ege Denizi) biyoçeşitliliği. Acta Aquatica Turcica, 16(3), 313-329 https://doi.org/10.22392/actaquatr.677175

Özet

Bu çalışmada, Gökçeada kıyılarında 22,4 - 24,8 m derinlikleri arasında bulunan TCSG-132 isimli gemi batığı üzerindeki ve çevresindeki denizel biyolojik çeşitliliğin belirlenmesi amaçlanmıştır. Bu kapsamda Ekim 2018 - Eylül 2019 tarihleri arasında sualtında türleri tanıyabilme yeteneğine sahip dalgıçlar düzenli olarak SCUBA takımları ile dalışlar gerçekleştirmiştir. Dalışlar süresince verilerin elde edilmesinde görsel sayım teknikleri (transekt, nokta sayım, kuadrat), fotoğraf çekimleri ve video kayıtları kullanılmıştır. Çalışma sonucunda 19 familyaya ait 28 türden 12708 birey kaydedilmiştir. Bunların içinde 15 türün ekonomik öneme sahip olduğu belirlenmiştir. En çok gözlenen türlerin balıklardan kupes (Boops boops, \%44,55), papaz (Chromis chromis, \%26,44) ve izmarit (Spicara maena, \%15,50) olduğu tespit edilmiştir. Sonuç olarak, TCSG-132 gemi batığının denizel türler için önemli bir yapay resif olarak hizmet ettiği ve canlılara yaşama, sığınma, yumurtlama, beslenme ve koruma imkanları sağladığı belirlenmiştir.

Anahtar kelimeler: Gemi batığı, yapay resif, görsel sayım, biyolojik çeşitlilik, Ege Denizi

Biodiversity of TCSG-132 Shipwreck Artificial Reef (Gökçeada, North Aegean Sea)

\begin{abstract}
In this study, it was aimed to determine the species composition and marine biodiversity on and around the TCSG-132 shipwreck, which was located between 22.4 and $24.8 \mathrm{~m}$ depths in the coasts of Gökçeada Island. In this context, aquanauts regularly conducted SCUBA-equipped dives between October 2018 and September 2019. Visual counting techniques (transect and point-count (quadrat)), photo shoots and video recordings were used to obtain the data during the dives. As a result of the study, 12708 individuals from 28 different species belonging to 19 families were recorded. Among these, 15 species were determined to have economic importance. The most commonly observed species were bogue (Boops boops, 44.55\%), damselfish (Chromis chromis, 26.44\%) and blotched picarel (Spicara maena, 15.50\%). In conclusion, TCSG-132 shipwreck has been found to serve as an important artificial reef for marine species and to provide living, sheltering, spawning, feeding and conservation opportunities for marine species.
\end{abstract}

Keywords: Shipwreck, artificial reef, visual census, biological diversity, Aegean Sea

\section{GíRiş}

Denizel biyoçeşitlilik, farklı yapısal ve işlevsel özelliklere sahip çeşitlilikte genlerden, türlerden, popülasyonlardan ekosistemlere kadar her türlü biyolojik topluluğu kapsayan birbirine bağl1 ekosistem bileşenlerinin veya özelliklerinin bir araya getirilmesidir (Cochrane vd., 2016). Ayrıca, denizel biyolojik çeşitlilik veya bileşenlerinden herhangi biri, çeşitli zamansal veya mekansal ölçeklerde değerlendirilebilir. Denizel türlerin çeşitliliğindeki değişimler, denizel biyoçeşitlilik ve ekosistemin bozulmasına neden olabilmekte ve ticari balıkçılık faaliyetlerini de etkilemektedir (Roessig vd., 2004; Worm vd., 2006; Cheung vd., 2008). Tür çeşitliliğinin alansal ve/veya zamansal olarak değişkenlik göstermesi biyoçeşitlilik, topluluk yapısı ve ekosistem fonksiyonları üzerinde önemli etkilere sahiptir (Sala vd., 2000; Stachowicz vd., 2002; Hooper vd., 2005). Fricke vd. (2020) dünya genelinde doğruluğu geçerli olan toplam 35401 denizel canlı türünün belirlenmiş olduğunu bildirmektedir. 
Denizel canlıların alansal/zamansal dağılımları, bulundukları bölgelerdeki çeşitliliğinin araştırılması balıkçılık kaynaklarının sürdürülebilirliğinin sağlanabilmesi açısından büyük önem taşımaktadır.

Yapay resifler denizel canlılarının bulunduğu mevcut habitatları koruyup geliştirmek veya seçenekli bir yaşam alanı sağlamak için denizlere yerleştirilen yapılar şeklinde ifade edilmektedir (Jensen, 2002). Denizlerdeki bu yapay resifler canlılar için potansiyel barınma, üreme, beslenme ve korunma gibi yaşamsal fonksiyonlar açısından seçenekli yaşam alanları sunmaktadır. Yapay resifler biyoçeşitliliğin korunması, bütünleşik kıyı alanları yönetimi, canlı deniz kaynaklarından sürdürülebilir bir şekilde yararlanılması, etkili balıkçılık yönetimi faaliyetlerinin gerçekleştirilebilmesi gibi amaçlar doğrultusunda önem arz etmekte ve büyük ilgi görmektedir.

Yapay resiflerin balıkçılık ve çevreyle olan etkileşimleri (Brennan vd., 2011, 2016; Bulleri vd., 2005; Krumholz ve Brennan, 2015; Jimenez vd., 2016), türe özgü yapay resif çalışmaları (Ulaş vd., 2011; Özgül vd., 2017; Acarlı vd., 2018; Acarlı ve Kale, 2020a) balık tür çeşitliliğinin belirlenmesi (Gül vd., 2006; Honorio vd., 2010; Krumhalz vd., 2015) gibi çalışmalar özellikle görsel sayım yöntemleri (SCUBA dalış ekipmanları veya uzaktan kumandalı araçlar kullanılarak) (Ulaş vd., 2007; Simon vd., 2010; Genzano vd., 2011; Altınağaç vd., 2013; Acarli ve Ayaz, 2015; Horasanl1, 2016; Kocabaş ve Acarlı, 2019) ve uzatma ağ1, olta vb. av araçları kullanılarak gerçekleştirilmiştir. Yapay resiflerdeki tür çeşitliliğinin belirlenmesine yönelik çalışmalarda çoğunlukla sualtı görsel sayım yöntemleri kullanılmaktadır. Yapay resiflerin bulunduğu alanlarda görsel sayım teknikleri kullanılarak gerçekleştirilen bazı çalışmalarda yapay resiflerin balık toplulukları üzerindeki etkisi araştırılmıştır (Lök vd., 2002; Gül vd., 2006; Lok vd., 2007; Lök vd., 2008; Gül vd., 2011; Özgül ve Lök., 2017). Ayrıca görsel sayım tekniği ile balık türlerinin ve deniz memelilerinin gözlemlenmesi (Gücü ve Erkan, 2005; Akça, 2010; Acarli vd., 2013), deniz koruma alanlarının belirlenmesi (Sakinan ve Gucu, 2010), hayalet ağların belirlenmesi (Ayaz vd., 2010), balık cezbedici düzeneklerin (FAD) etkisinin belirlenmesi (Özalp, 2009; Lök ve Özgül, 2010; Acarlı vd., 2019a; Acarlı vd. 2019b) ve yabanc1 türlerin incelenmesi (Sala vd., 2011; Bodilis vd., 2014) üzerine de çalışmalar gerçekleştirilmiştir.

Gökçeada kıyılarında ise balık faunası, tür çeşitliliği ve türlerin alansal dağılımları üzerine çalışmalar yapılmıştır (Keskin ve Ünsal, 1998; Keskin, 2004; Karakulak vd., 2006; Keskin ve Oral, 2007; Türetken, 2009; Cengiz vd., 2011; Y1ldı vd., 2012; Kale vd., 2014a; Kale vd., 2014b; Kale vd., 2014c; Altın vd., 2015; Kale vd., 2015a; Kale vd., 2015b; Horasanl1, 2016; Bektaş, 2017). Doğal resifler çevresindeki balık faunasının belirlenmesi için de gerçekleştirilmiş çalışmalar bulunmaktadır (Karakulak vd., 2006; Keskin ve Oral, 2007; Türetken, 2009; Yıldız vd., 2012; Altın vd., 2015; Horasanl1, 2016). Ancak, yapay resiflerdeki tür çeşitliliğinin belirlenmesi üzerine herhangi bir çalışma bulunmamaktadır.

Bu çalışmada, Kuzey Ege Denizi'nin Gökçeada kıyılarında 22,4 - 24,8 m derinlikleri arasında bulunan TCSG-132 isimli gemi batığ 1 üzerindeki ve çevresindeki tür kompozisyonu ve denizel biyolojik çeşitliliğin belirlenmesi amaçlanmıştır. Yapay resifin sualtı tür çeşitliliği üzerindeki etkisi görsel sayım teknikleri ile incelenmiştir.

\section{MATERYAL ve YÖNTEM}

Çalışma Ekim 2018 - Eylül 2019 tarihleri arasında Gökçeada'nın kuzeyinde bulunan Ördek Yalağı mevkiinde (Şekil 1) 22,6 - 24,8 m derinlikleri arasında yer alan TCSG-132 (Şekil 2) isimli gemi batığı üzerinde ve çevresinde gözlemler yapılarak gerçekleştirilmiştir. TCSG-132 isimli gemi, Türkiye Cumhuriyeti Sahil Güvenlik Komutanlığı'ndaki hizmetlerinden sonra hurdaya ayrılmıştır. Gemi, denizde olumsuz etkiler yaratabilecek kirleticilerden (cam, ahşap, yağ, yakıt deposu vb.) temizlendikten sonra, 24 Ekim 2016 tarihinde Gökçeada Belediyesi ve Gökçeada Kaymakamlığı'nın ortak çalışmaları sonucunda batırılmıştır (Şekil 2). Geminin boyu 40,3 m eni 6,4 m olup baş kısmı 22,6 m derinlikte, kıç tarafı ise 24,8 m derinlikte kısmen deniz çayırlarının (Posidonia oceanica) bulunduğu zeminde kıyıya paralel bir şekilde durmaktadır. 


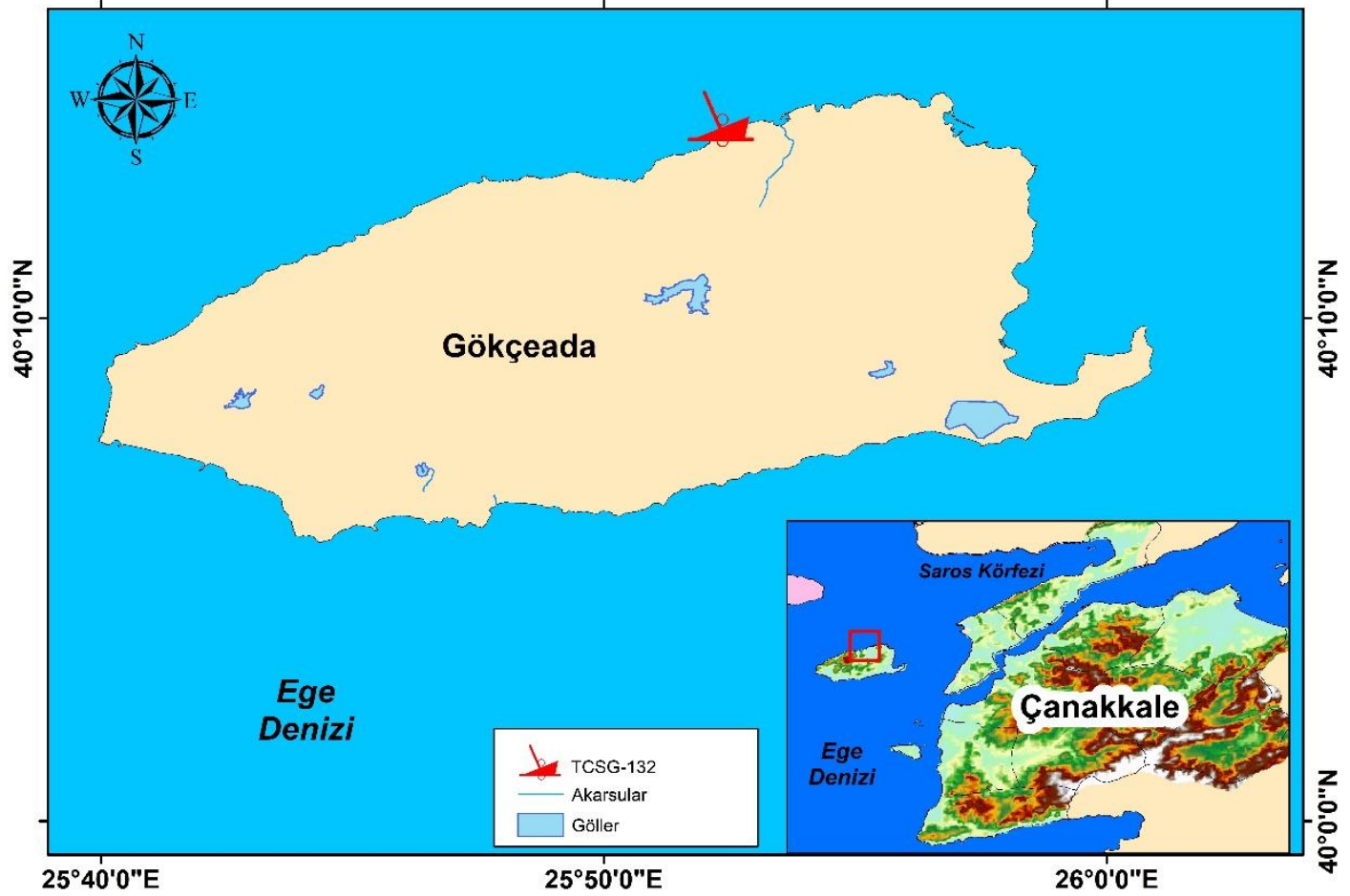

Şekil 1. TCSG-132 gemi batığ 1 yapay resifinin konumu

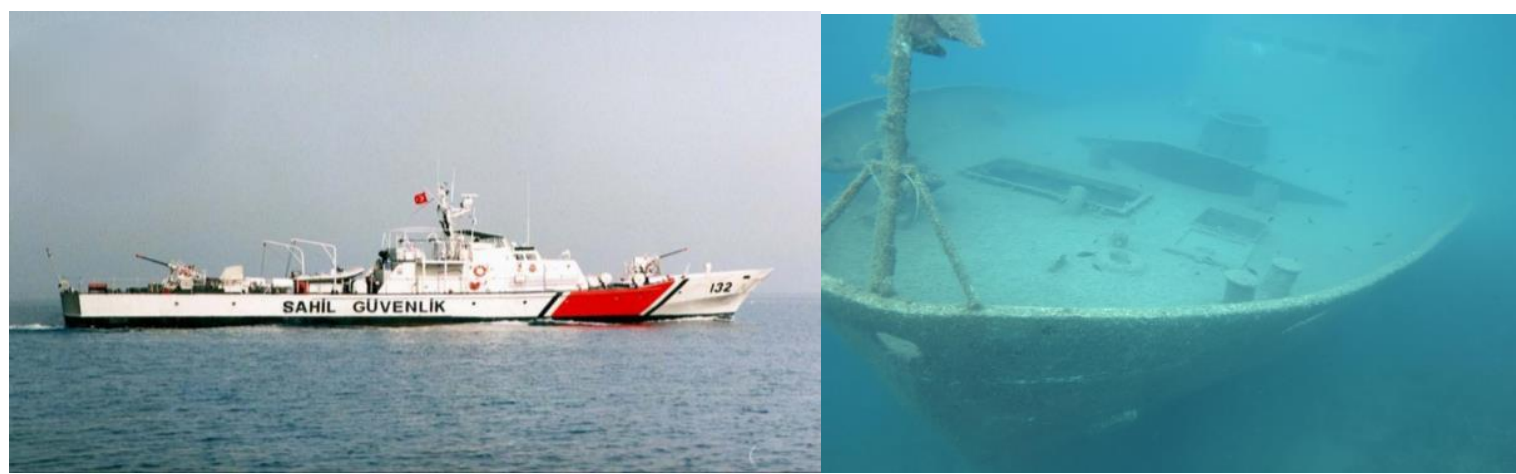

Şekil 2. TCSG-132 isimli geminin çalışır durumdayken ve batırıldıktan sonra sualtındaki görünümü

Yapılan çalışmalar sırasında batık bölgesine ulaşım için Çanakkale Onsekiz Mart Üniversitesi Gökçeada Uygulamalı Bilimler Yüksekokulu'na ait ÇOMÜ-3 isimli tekne kullanılmıştır. Çalışma 12 ay boyunca aylık olarak SCUBA dalış takımları kullanılarak gerçekleştirilmiştir. Çalışma süresince hangi görsel sayım yöntemlerinin ve av araçlarının kullanılacağı yapılan ön çalışmalarla belirlenmiştir. Aylık olarak yapılan bu dalışlarda sualtında türleri ayırt edebilecek tecrübeye sahip iki dalgıç görev almıştır (Acarli ve Ayaz, 2015). Dalışlar hava şartlarına bağlı olarak her ayın 10'u ila 20'si arasındaki günlerde aynı saat aralıklarında (10.00-12.00) yapılmıştır. Araştırma boyunca verilerin elde edilmesinde sualtı görsel sayım teknikleri olarak transekt ve kuadrat yöntemlerinden (Harmelin-Vivien ve Harmelin, 1975) yararlanılmıştır. Ayrıca sualtı video kayıt ve fotoğraf makinesi (GoPro Hero 4) kullanılmıştır.

Elde edilecek verilerin daha sağlıklı olması maksadıyla, dalışların balıklara olumlu ve olumsuz etkileri olabileceği düşünülerek video kaydı ve fotoğraf çekimleri en fazla 15 dakikalık sürelerde yapılmıştır. Çalışma sırasında türlerin batık çevresinde tercih ettiği bölgelerin belirlenmesi açısından gemi batığı üç bölüme ayrılmış ve (i) dış-alt bölge (batı̆̆ın deniz tabanıyla birleştiği bölge), (ii) dış-üst bölge (batığın güverte kısmı ve üstündeki açık alan), (iii) iç bölge (geminin kaptan köşkü ve sintine gibi iç kısımlarını kapsayan bölge) olarak sınıflandırılmıştır (Şekil 3). 


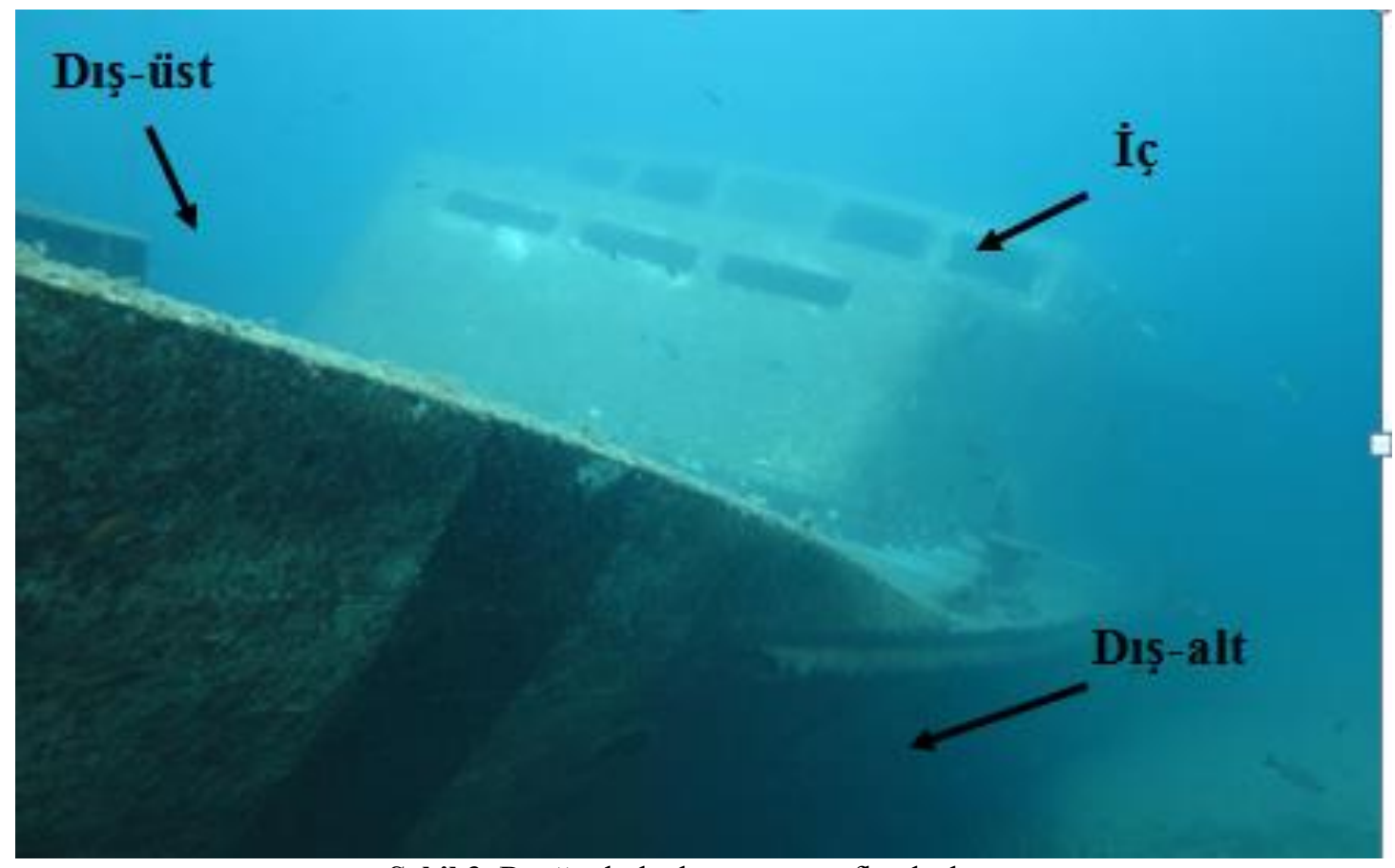

Şekil 3. Batığın bölgelere göre sınıflandırılması

Dalışlar sırasında balık türleri, birey sayısı, su sıcaklığı ve görüş mesafesi anlık olarak sualtı yazı araçlarına yazılmıştır. Yapılan dalışlarda yüzey ve dipteki su sıcaklıkları dalış bilgisayarı (Oceanic CEO2) ile ölçülmüştür.

Gözlenen bireylerin hangi türler olduğunun bilimsel olarak belirlenmesinde sualtında türleri tanıyabilme yeteneğine sahip dalgıçların batık çevresindeki türlerin tespit edilmesi konusundaki tecrübelerinden yararlanmanın yanında çekilen fotoğraf ve video kayıtları ayrıntılı olarak incelenerek türlerin belirlenmesinde Bilecenoğlu vd. (2014), Öztürk vd. (2014) ve Bakır vd. (2014) kaynaklarından da yararlanılmıştır.

Tür çeşitliliği için birçok farklı indeks bulunmakla beraber bu indekslerin hesaplamalarında genellikle tür sayısı ve birey adetleri kullanılmaktadır. Bu Çalışmada Shannon çeşitlilik indeksi $(\mathrm{H})$ kullanılmıştır. Kullanılan biyoçeşitlilik indeksi şu eşitlikten yararlanılarak hesaplanmaktadır:

$$
H=\sum_{i=1}^{5}\left(p_{i}\right)\left(\ln p_{i}\right)
$$

$\mathrm{Bu}$ eşitlikte $p_{i}=\mathrm{i}$ türüne ait miktarın toplam örnek miktarına oranını ifade etmektedir.

Tür kompozisyonunda mevsimsel farkl1lı̆̆ oluşturan başlıca türlerin tespit edilmesi için SIMPER istatistiksel analizi kullanılmıştır. Biyoçeşitlilik ve istatistiksel analizler PAST versiyon 3.1 (Hammer vd., 2001) paket programı ile yapılmıştır. Mevsimlere göre birey sayılarının arasındaki ilişkinin görselleştirilmesi amacıyla MDS analizi yapılmıştır. MDS ölçeklendirmede koordinatların uzaklıklarının hesaplanması için Bray-Curtis formülü kullanılmıştır. Birey adetleri ile yapılan analizlerde logaritmik $(\log (\mathrm{n}+1))$ dönüşüm gerçekleştirilmiştir.

\section{BULGULAR}

Araştırma süresince aylık olarak SCUBA ekipmanları kullanılarak yapılan dalışlar ile elde edilen veriler sonucunda 19 familyaya ait 28 tür ve bu türlerin 12708 bireyi kaydedilmiştir (Tablo 1). Sualtı gözlemleri boyunca tespit edilen 28 türün \%51,7'sinin ekonomik öneme sahip olduğu belirlenmiştir (Tablo 1). Bu türler Sparidae familyasından kupes (Boops boops), karagöz (Diplodus vulgaris), sargoz (Diplodus sargus), 1sparoz (Diplodus annularis) ve 1skatari (Spondyliosoma cantharus), Mullidae familyasindan barbunya (Mullus barbatus barbatus) ve tekir (Mullus surmulatus), Centracanthidae familyasından izmarit (Spicara maena), Sciaenidae familyasında işkine (Sciaena umbra) ve Labridae familyasından kikla (Labrus bergylta)'dır. Balıkların dışında batıkta Akdeniz midyesi veya kara midye (Mytilus galloprovincialis), istiridye (Ostrea edulis), boru kurdu (Diopatra sp.) ve madya (Hexaplex trunculus) da tespit edilmiştir. 
Ayrıca, Dünya Doğa ve Doğal Kaynakları Koruma Birliği (IUCN) tehdit altındaki türlerin kırmızı listesinde hassas (vulnerable) olarak yer alan Caretta caretta türü de batığın bulunduğu bölgede gözlemlenmiştir (Kocabaş ve Acarl1, 2019).

Tablo 1. TCSG-132 batığında tespit edilen türler

\begin{tabular}{|c|c|c|c|}
\hline Familyalar & Türler & Birey Sayısı & Ekonomik Değer \\
\hline Sparidae & Iskatari (Spondyliosoma cantharus) & 77 & $*$ \\
\hline Sparidae & Karagöz (Diplodus vulgaris) & 752 & $*$ \\
\hline Sparidae & Sargoz (Diplodus sargus) & 53 & $*$ \\
\hline Sparidae & Kupes (Boops boops) & 5290 & $*$ \\
\hline Sparidae & Isparoz (Diplodus annularis) & 156 & * \\
\hline Labridae & Kikla (Labrus bergylta) & 14 & $*$ \\
\hline Labridae & Gelin balığı (Coris julis) & 197 & \\
\hline Labridae & Çırçır (Symphodus melops) & 65 & \\
\hline Labridae & Çırçır (Symphodus tinca) & 78 & \\
\hline Serranidae & Asıl hani balığ1 (Serranus cabrilla) & 57 & \\
\hline Serranidae & Çizgili hani balığı (Serranus scriba) & 66 & \\
\hline Mullidae & Barbunya (Mullus barbatus barbatus) & 3 & $*$ \\
\hline Mullidae & Tekir (Mullus surmuletus) & 6 & $*$ \\
\hline Centracanthidae & İzmarit (Spicara maena) & 1990 & * \\
\hline Sciaenidae & İşkine (Sciaena umbra) & 54 & $*$ \\
\hline Gobiidae & Kaya balığı (Gobius sp.) & 7 & \\
\hline Pomacentridae & Papaz balı̆̆ (Chromis chromis) & 3640 & \\
\hline Congridae & Migri (Conger conger) & 1 & \\
\hline Blenniidae & Horozbina (Parablennius sp.) & 1 & \\
\hline Phycidae & Gelincik (Phycis phycis) & 2 & \\
\hline Loliginidae & Kalamar (Loligo vulgaris) & 1 & \\
\hline Nephropidae & Istakoz (Homarus gammarus) & 1 & $*$ \\
\hline Mytilidae & Akdeniz midyesi (Mytilus galloprovincialis) & 150 & $*$ \\
\hline Ostreidae & İstiridye (Ostrea edulis) & 15 & $*$ \\
\hline Muricidae & Madya (Hexaplex trunculus) & 1 & $*$ \\
\hline Turritellidae & Deniz minaresi (Turritellinella tricarinata) & 1 & \\
\hline Onuphidae & Boru kurdu (Diopatra sp.) & 15 & $*$ \\
\hline Aplysiidae & Deniztavşanı (Aplysia sp.) & 15 & \\
\hline
\end{tabular}

Çalışma boyunca yapılan dalışlarda görüş mesafeleri kaydedilmiş, $5 \mathrm{~m}$ ile $20 \mathrm{~m}$ arasında değişiklik gösterdiği belirlenmiștir. Görüş mesafesinin 5 m'nin altına düşmemesinin görsel sayım açısından olumlu olduğu düşünülmektedir.

Sparidae familyasının 5 farklı tür ile en fazla türün gözlendiği familya olduğu ve toplamın \%17'sini kapsadığı belirlenmiştir. Bu familyayı 4 tür ile Labridae familyası (\%14) takip etmektedir. Serranidae ve Mullidae familyalarına ait 2 tür, Centracanthidae, Nephropidae, Phycidae, Aplysiidae, Muricidae, Turritellidae, Onuphidae, Blenniidae, Gobiidae, Pomacentridae, Congridae, Sciaenidae, Mytilidae, Loliginidae ve Ostreidae familyalarına ait ise sadece 1'er tür tespit edilmiştir (Şekil 4). 


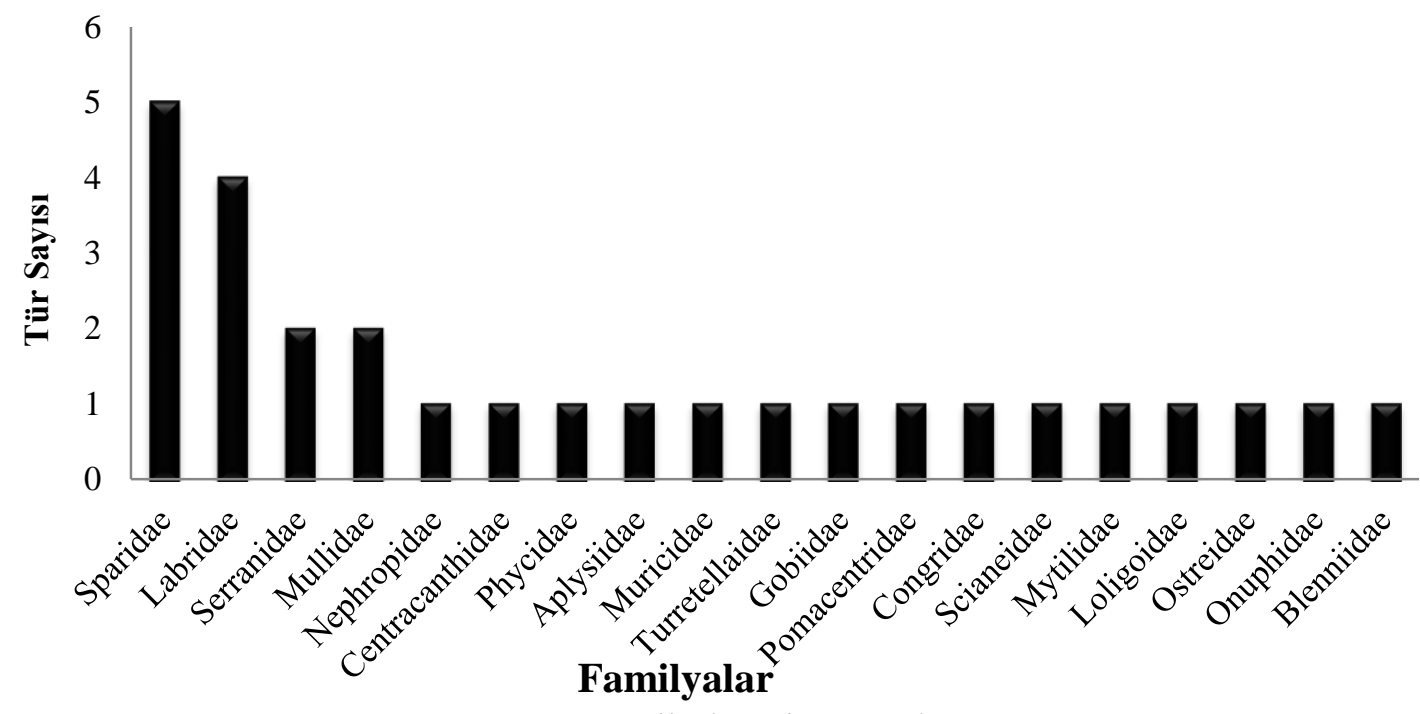

Şekil 4. Familyalara ait tür sayıları

Elde edilen bulgular incelendiğinde tür sayısı bakımından çeşitlilik en fazla Kasım ayında 19 tür olarak belirlenmiş, en az çeşitlilik ise 7 tür ile Ocak ayında gözlenmiştir (Şekil 5).

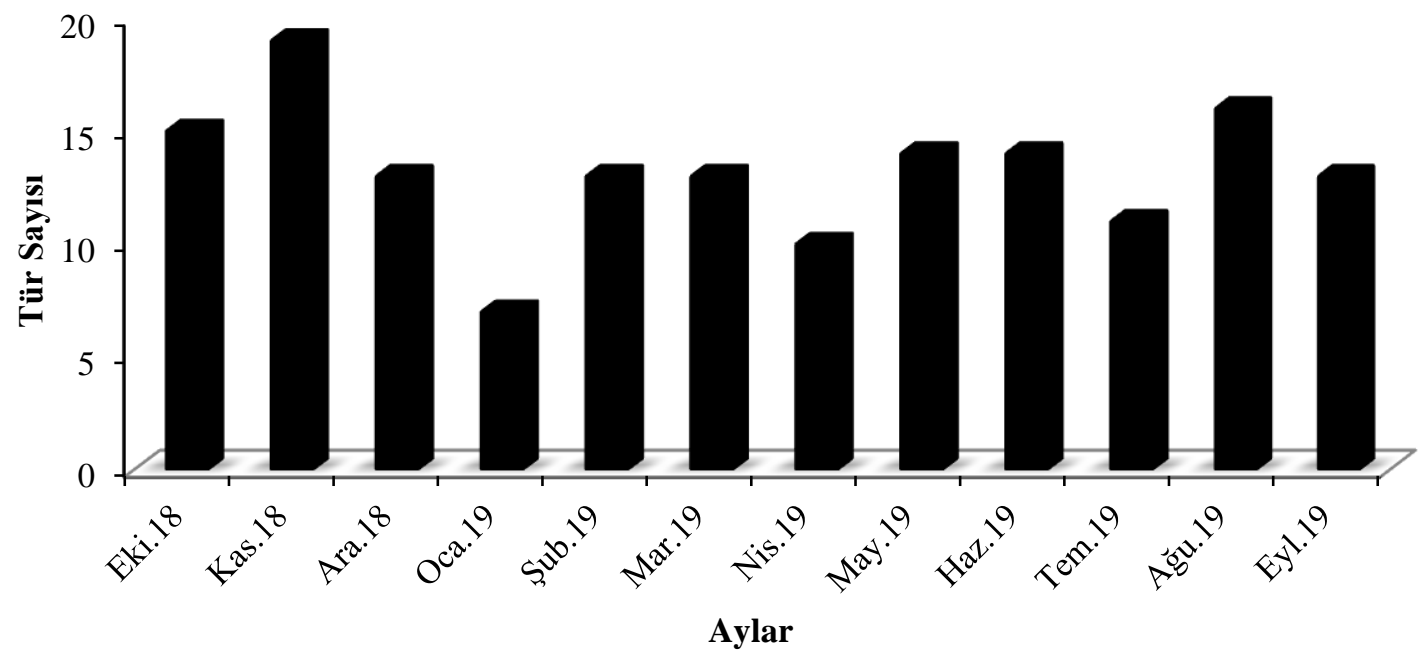

Şekil 5. Aylık tür sayıları

Birey sayısında bolluk en fazla 4196 birey ile Mart ayında, en az ise 291 birey ile Şubat ayında kaydedilmiştir (Şekil 6). Ayrıca, mevsimsel olarak tespit edilen birey sayıları da belirlenmiştir (Şekil 7). Toplam 12708 birey içerisinde en çok gözlenen ve toplamın \%94'ünü oluşturan ilk 5 tür ve bunların miktarları Şekil 8'de gösterilmiştir. 


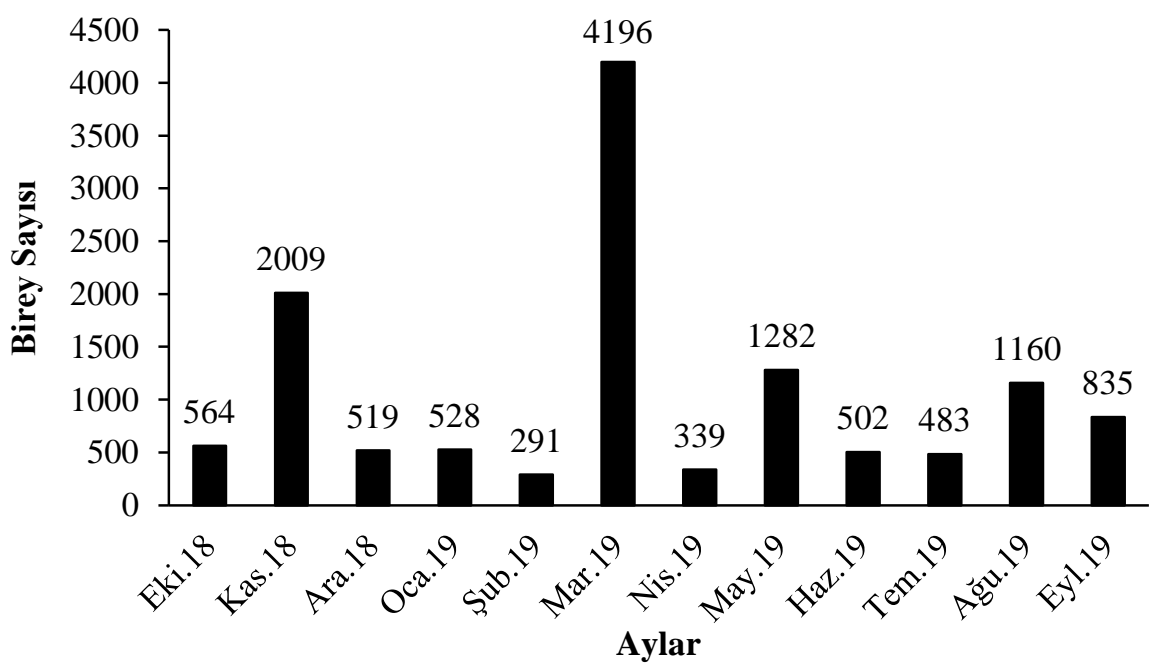

Şekil 6. Aylık birey sayıları

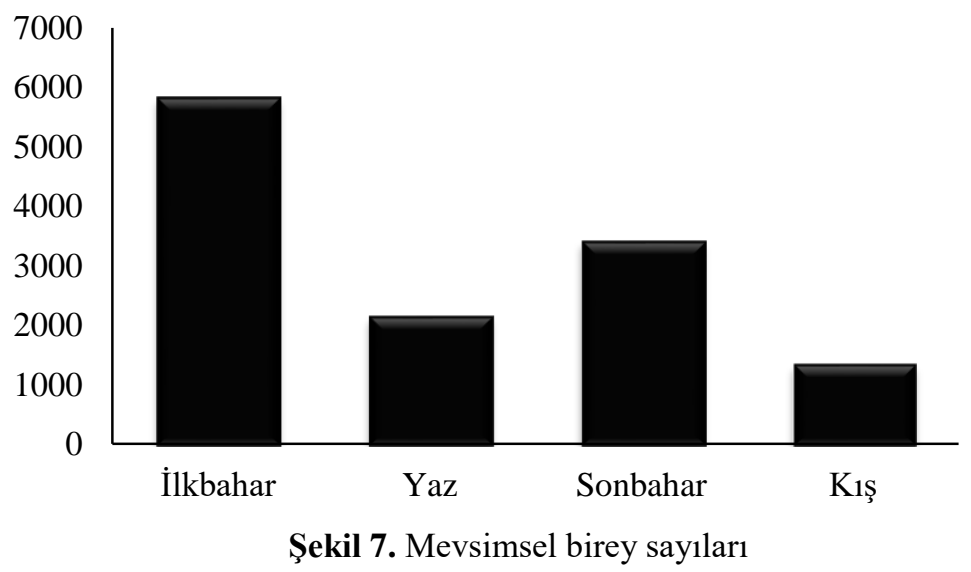

Batık civarında gözlenen türler arasında en sik gözlenen türlerin kupes (B. boops), izmarit $(S$. maena), karagöz (D. vulgaris), papaz (C. chromis) ve gelin balı̆̆ı $(C$. julis) türleri olduğu tespit edilmiştir (Şekil 8).

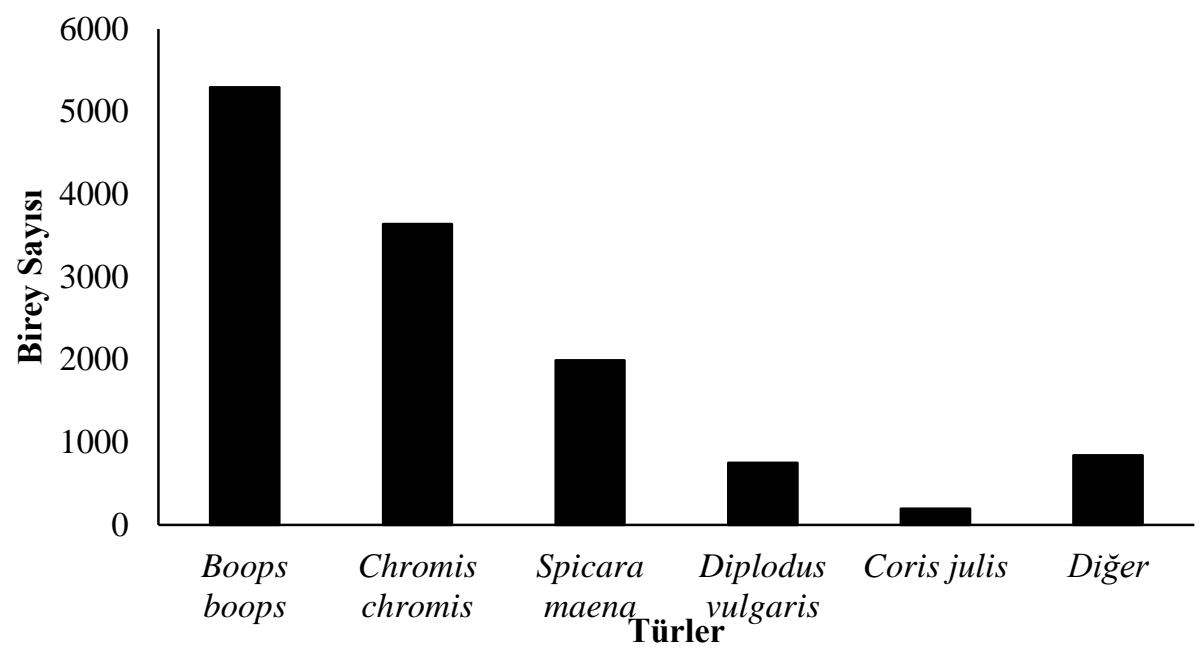

Şekil 8. En çok gözlenen 5 tür ve miktarları

Çalışma sırasında yapılan bölgesel sınıflandırma kapsamında türlerin gemi batığı etrafındaki dağılım oranları belirlenmiş ve Şekil 9'da gösterilmiştir. Tercih ettiği bölgeler belirlenen türlerin toplam birey sayılarının bölgelere göre dağılımları hesaplanmıştır (Şekil 10). 


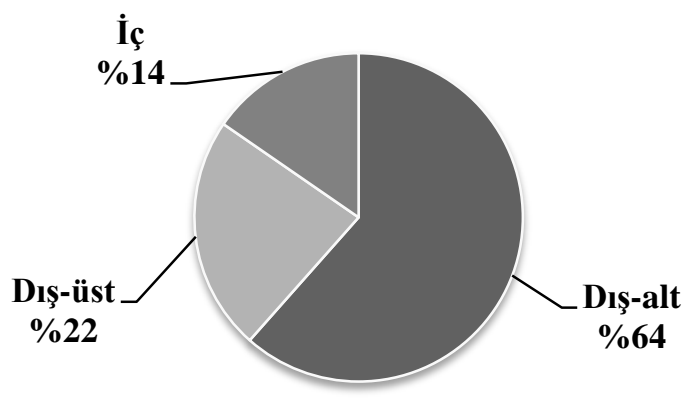

Şekil 9. Bölgelere göre türlerin dağılım oranları

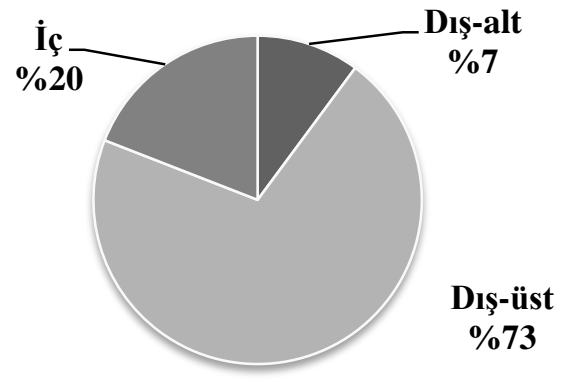

Şekil 10. Bölgelere göre birey sayılarının dağılım oranları

Batık bölgesindeki yüzey ve dip suyu sıcaklıkları aylık dönemler şeklinde kaydedilmiştir. Çalışma süresince hem yüzey suyu hem de dip suyu için en düşük sıcaklık $13^{\circ} \mathrm{C}$ olarak belirlenirken en yüksek sıcaklık dip suyu için $26^{\circ} \mathrm{C}$ ve yüzey suyu için $27^{\circ} \mathrm{C}$ olarak ölçülmüştür (Şekil 11). Ayrıca, dip suyu sıcaklığı ile tür sayısının aylık değişimi ve aralarındaki ilişki Şekil 12'de sunulmuştur.

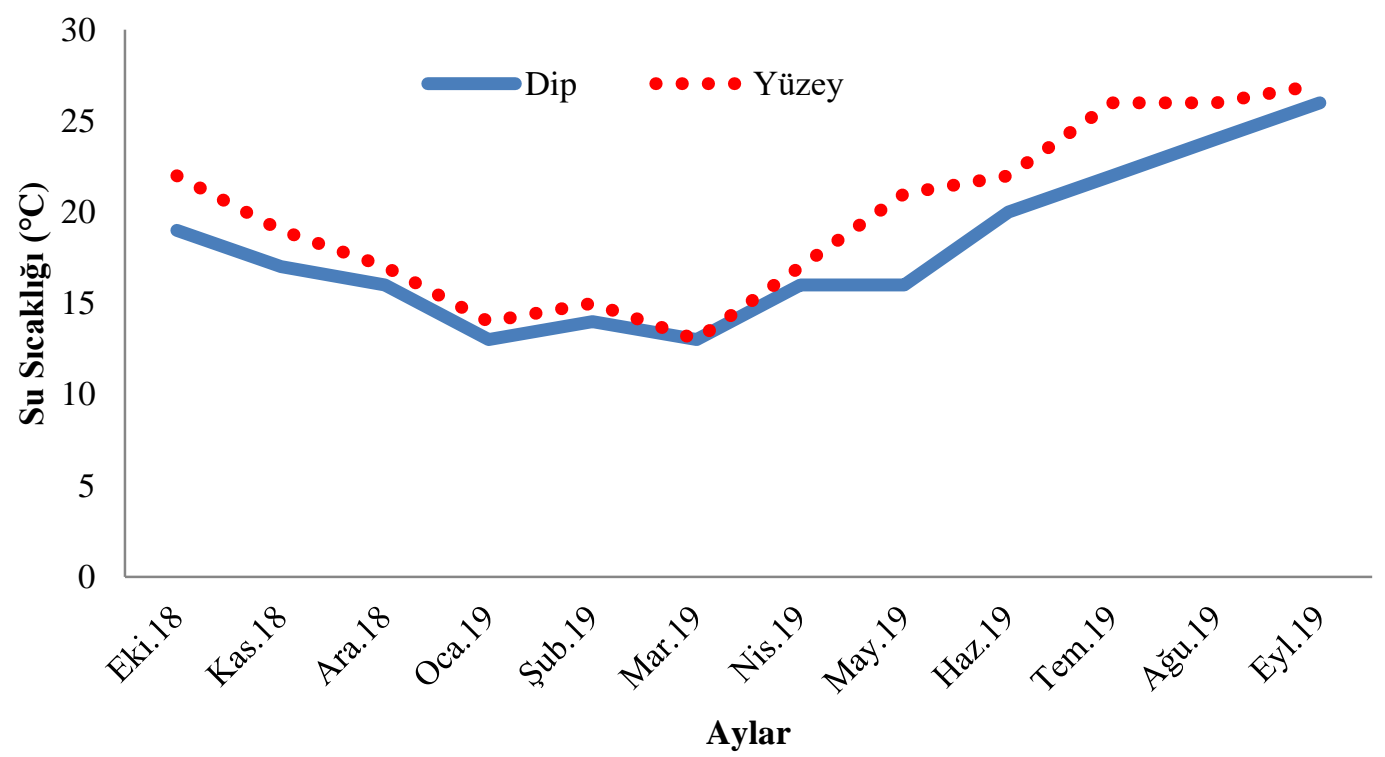

Şekil 11. Yüzey ve dip suyu sıcaklığının aylık değişimi 


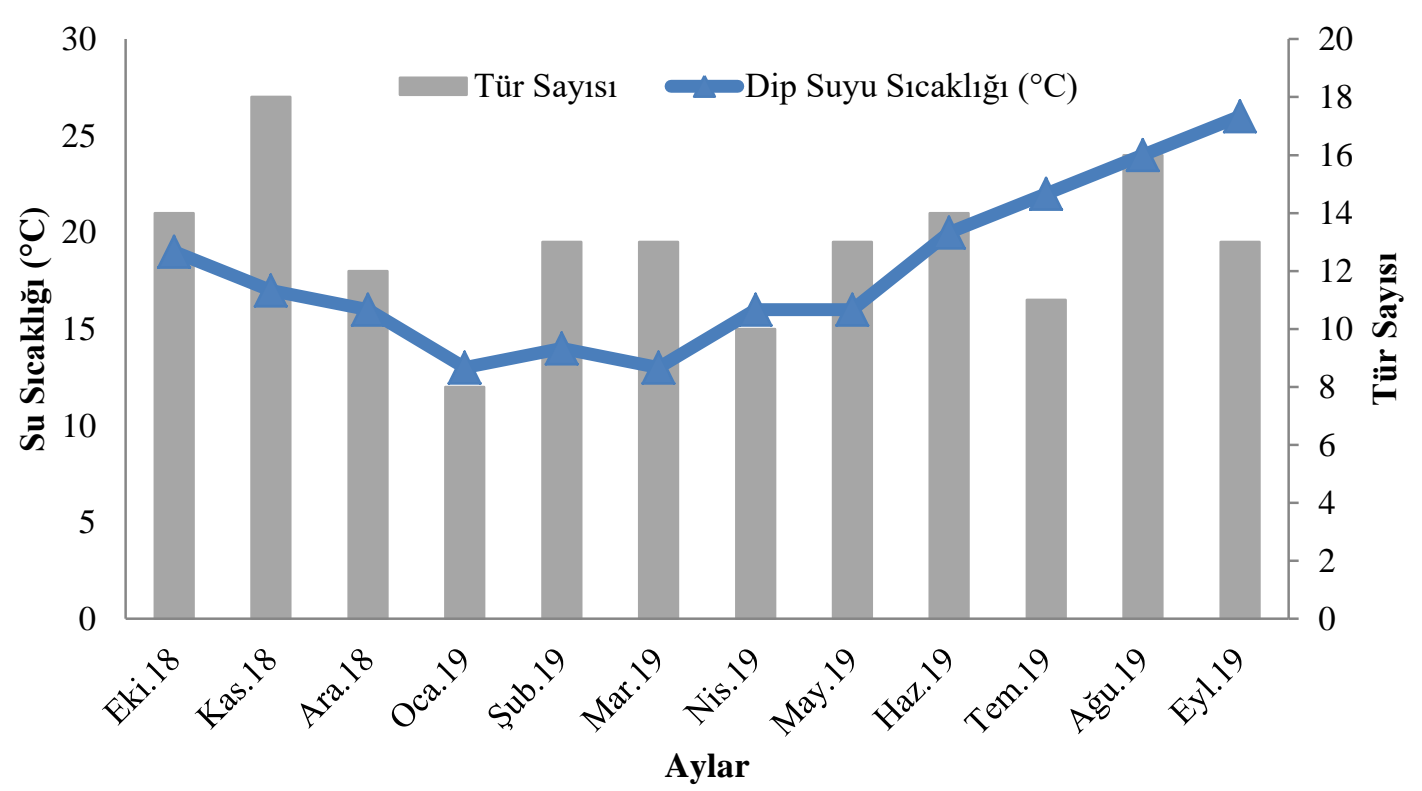

Şekil 12. Dip suyu sıcaklığı ve tür sayısı arasındaki aylık değişimleri arasındaki ilişki

Çalışmada elde edilen bulgular kullanılarak biyoçeşitlilik indeksi hesaplanmıştır. Biyoçeşitlilik indeksinin hesaplanmasında Shannon-Weaner biyoçeşitlilik indeksi kullanılmıştır. Analiz sonuçlarına göre Shannon-Weaner biyoçeşitlilik indeksi en düşük ilkbahar mevsiminde ve en yüksek ise sonbahar mevsiminde tespit edilmiştir. Ayrıca, Jacard'ın düzenlilik indeksi en düşük ilkbahar mevsimi ve en yüksek kış mevsiminde hesaplanmıştır (Tablo 2).

Tablo 2. Gemi batığı civarındaki mevsimsel biyoçeşitlilik indeksi ve Jacard'ın düzenlilik indeksi.

\begin{tabular}{lccccc}
\hline \hline Mevsim & Tür Sayısı & Birey Sayısı & d & J' & H' $\left(\log _{2}\right)$ \\
\hline Sonbahar & 20 & 3558 & 2,32 & 0,59 & 2,57 \\
Kiş & 15 & 1418 & 2,07 & 0,61 & 2,43 \\
Ilkbahar & 18 & 5860 & 1,96 & 0,38 & 1,57 \\
Yaz & 22 & 2142 & 2,74 & 0,50 & 2,25 \\
\hline \hline
\end{tabular}

Mevsimsel olarak gerçekleştirilen Bray-Curtis benzerlik analizi sonuçları değerlendirildiğinde benzerlik oranı en fazla olan mevsimler ilkbahar ve sonbahar olarak belirlenmiştir. Bu iki mevsime benzerliği yönünden ise kış mevsiminin benzerliği yaz mevsiminin benzerliğinden daha yüksek olarak tespit edilmiştir. En düşük benzerlik oranı ise \%70 civarı yaz mevsimi için hesaplanmıştır (Şekil 13). Diğer taraftan, metrik çok boyutlu ölçekleme analizi (MDS) uygulanmış ve yaz mevsiminin diğer mevsimlerden ayrık olduğu tespit edilmiştir. (Şekil 14). 


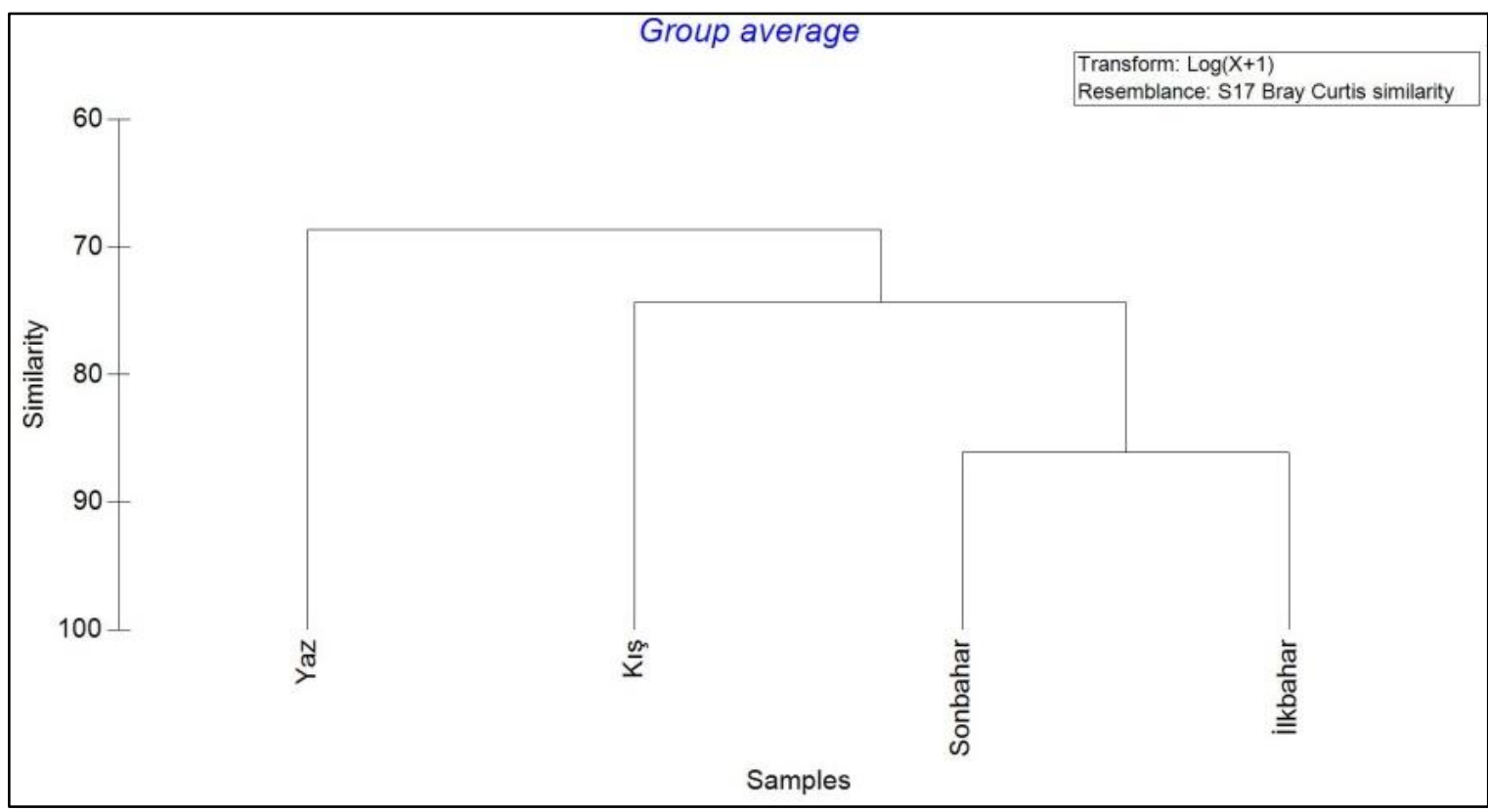

Şekil 13. Mevsimlere göre Bray-Curtis benzerlik dendogramı

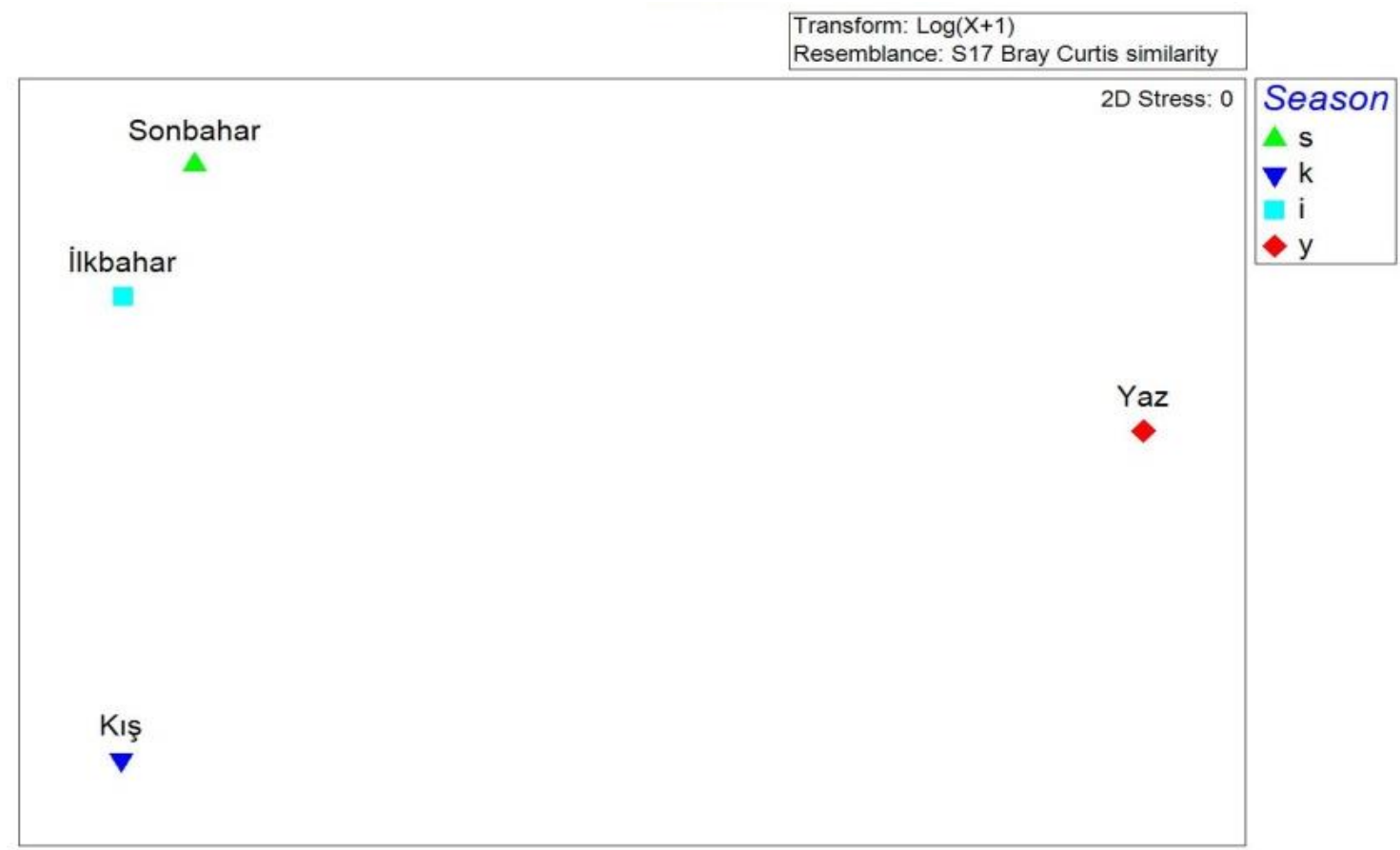

Şekil 14. Mevsimlerin birey sayılarına göre MDS dağılımı

Benzerlik yüzdeleri SIMPER analizi yapılarak mevsimler arasındaki farklılık oranları, bu farklara neden olan türler ve bu türlerin oranları belirlenmiştir. Bu farklılığı oluşturan başlıca türler ve farklılığın oluşmasındaki yüzde katkıları Tablo 3'te verilmiştir. 
Tablo 3. SIMPER analizi sonuçları

\begin{tabular}{|c|c|c|c|c|c|c|}
\hline Farklılık (\%) & $\begin{array}{c}\text { Yaz-Sonbahar } \\
(\% 29,26)\end{array}$ & $\begin{array}{l}\text { Yaz-Kış } \\
(\% 35,39)\end{array}$ & $\begin{array}{c}\text { Sonbahar- } \\
\text { Kış }(\% 26,81)\end{array}$ & $\begin{array}{c}\text { Yaz-İlkbahar } \\
(\% 29,41)\end{array}$ & $\begin{array}{l}\text { Sonbahar- } \\
\text { İlkbahar } \\
(\% 13,85)\end{array}$ & $\begin{array}{c}\text { Kış-İlkbahar } \\
(\% 24,50)\end{array}$ \\
\hline S. cantharus & & 11,39 & 14,32 & & 8,45 & 11,42 \\
\hline S. melops & & 6,97 & 10,72 & & & 13,44 \\
\hline S. tinca & & 6,25 & 10,72 & & & 12,22 \\
\hline C. bimaculatum & & & 7,76 & & & 9,32 \\
\hline M. surmuletus & 6,48 & & 5,84 & & 10,26 & \\
\hline Gobius sp. & & & & & 10,67 & \\
\hline S. maena & & & & & 9,03 & \\
\hline D. sargus & & & & & 8,82 & \\
\hline B. boops & & & & 9,95 & & 8,91 \\
\hline M.galloprovincialis & 12,67 & 11,05 & & 10,13 & & \\
\hline Aplysia sp. & 7,81 & 7,77 & & 8,43 & & \\
\hline D. annularis & 6,60 & & & 8,21 & & \\
\hline M. barbatus & 5,82 & & & 6,28 & & \\
\hline
\end{tabular}

\section{TARTIŞMA ve SONUÇ}

Gül vd. (2006) Ürkmez kıyılarında (Ege Denizi) yaptığı çalışmada 14-21 m derinliklerde bulunan yapay resiflerde görsel sayım yöntemleri kullanarak 12 familyaya ait 35 tür tespit etmiştir. $\mathrm{Bu}$ familyalar arasından Labridae (13 tür) ve Sparidae (9 tür) en baskın aileler olarak belirlenmiștir. Birey sayıları açısından ise en yüksek birey sayısının $C$. chromis, $S$. doderleini ve $B$. boops türlerinde kayıt edildiği bildirilmiştir. Mevcut çalışmada tespit edilen familya ve tür sayıları ile açısından ortaya çıkan farklılığın diğer çalışmada değişik derinliklerde bulunan resiflerde yapılan örneklemelerden kaynaklandığı düşünülmektedir. Buna karşın, baskın türler açısından iki çalışma paralellik göstermektedir. Ayrıca, en yüksek birey sayısına sahip türler bakımından da tek bir tür dışında (Symphodus doderleini) benzerlik göstermektedir. Bunun da her iki çalışmaların farklı bölgelerde ve su özelliklerine sahip alanlarda gerçekleştirilmesinden kaynaklandığı düşünülmektedir.

Gül vd. (2011) Ege kıyılarında (Gümüldür ve Ürkmez) yaptıkları çalışmada 20, 30 ve $40 \mathrm{~m}$ derinliklere yerleştirilmiş yapay resiflerde görsel sayım yöntemleri kullanarak 14 familyaya ait 30 tür tespit etmişlerdir. Tür ve familya zenginliği açısından $20 \mathrm{~m}$ derinlikteki resiflerin daha verimli olduğu bildirilmiştir. En çok tür Sparidae ve Serranidae familyalarında gözlenmiştir. En yaygın türler ise $C$. conger, $S$. cabrilla, S. scriba, M. barbatus, M. surmuletus, D. annularis, D. vulgaris, B. boops ve $C$. chromis olarak rapor edilmiştir. Aynı bölgede Ulaş vd. (2007) yaptığı çalışmada uzatma ağı, olta ve görsel sayım tekniklerini kullanarak 40 türe ait 2241 birey kaydetmiştir. En fazla birey sayısının (450 birey) C. chromis'e ait olduğu bildirilmiştir. Mevcut çalışma ile karşılaştırıldığında tür sayısında negatif bir fark olmasına karşın birey sayısı bakımından pozitif bir fark bulunmaktadır. Lök vd. (2008) İzmir kıyılarında iki farklı bölgede (Dalyanköy ve Gümüldür) görsel sayım yöntemi kullanarak $20 \mathrm{~m}$ derinlikte 23 familyaya ait 54 tür tespit etmiştir. En baskın familyalar Labridae ve Sparidae familyalarıdır. Mevcut çalışmada ise benzer derinliklerde ve görsel sayım yöntemleri ile çalışılmasına karşın familya ve özellikle birey sayılarında oldukça yüksek fark görülmektedir. Bu durumun nedeni, çalışmaların farklı bölgelerde yapılması ve örneklemelerde av araçlarının da kullanılmasından kaynaklandığ 1 ifade edilebilir.

Acarli ve Ayaz (2015) Ocaklar Koyu, Erdek Körfezi (Marmara Denizi) kıyılarında 2 sene boyunca görsel sayım teknikleri kullanarak 35 familyaya ait 51 tür gözlendiğini rapor etmiştir. Bu taksonlardan; 31 balık türü, 11 kabuklu türü, 3 derisidikenliler türü, 3 çift kabuklu türü, 2 denizanası türü ve 1 adet sünger türü olduğu bildirilmiştir. Söz konusu araştırmada tespit edilen familya ve tür sayısı açısından da farklılık göstermektedir. Familya ve tür sayılarındaki fazlalığın çalışmanın farklı bölgede gerçekleştirilmesi ve izleme süresinin uzunluğundan kaynaklandığ d düşünülmektedir.

Birey sayılarına bakıldığında, Keskin (1996) mevsimsel olarak en yüksek birey sayısını ilkbaharda 1310 birey, en düşük birey sayısını sonbahar ayında 361 birey olarak kaydetmiştir. Keskin ve Ünsal (1998) ise en düşük birey sayısını kış mevsiminde 847 birey, en yüksek yaz mevsiminde 773 birey olarak belirlemiştir. Gül vd. (2006) ise birey sayısı bakımından en yüksek değerleri yaz ve sonbahar mevsimlerinde bildirmiş̧ir. Mevcut çalışmada en yüksek değer ilkbaharda 5817 birey, en düşük değer 
985 birey ile yaz mevsiminde kaydedilmiştir. Oluşan farkın mevcut çalışmanın sabit derinlikte gerçekleştirilmesinden kaynaklandığ tahmin edilmektedir.

Batık çevresinde bulunan türlerin ve bu türlere ait bireylerin batık civarındaki bulunduğu bölgelere göre konumsal sınıflandırılması yapılmıştır. Tür bazında bakıldığında en çok diş-alt bölgesi (\%58) tercih edilmiş, bunu iç bölge takip etmektedir (\%26). Türlerin en az tercih ettiği bölge ise diş-üst (\%16) bölgededir. Buna karşın, birey sayısı bakımından tercih edilen bölgeler sırasıyla; dış-üst (\%73), iç (\%20), dış-alt (\%7) olarak belirlenmiştir. Bölgelere göre dağılımlara bakıldığında tür ve birey sayıları arasındaki zıtlığın özellikle gemi batığının dış-alt bölgesini tercih eden türlerin sürü oluşturmayan türler olmasından kaynaklanmaktadır. Literatürde denizel canlıların yapay resiflerin etrafinda bulundukları konumlara göre sinıflandırma yapılarak tür kompozisyonunun belirlenmesi üzerine herhangi bir çalışma bulunmadığından herhangi bir karşılaştırma yapılamamaktadır. $\mathrm{Bu}$ yönüyle de mevcut çalışma ilk olma özelliği taşımakta ve ayrı bir önem arz etmektedir.

Çoker ve Akyol (2018) Saroz Körfezi ve Gökçeada kıyılarında 1998-2018 yılları arasında yapılan çalışmaları derlemiş ve 96 familyaya ait 280 balık türünün rapor edildiğini bildirmiştir. Mevcut çalışmada gözlenen balık türlerinin tamamı da bu raporda yer almaktadır. Diğer yandan, literatürdeki Gökçeada kıyılarında tür çeşitliliğinin belirlenmesine yönelik çalışmalar (Keskin, 1996; Keskin ve Ünsal, 1998; Keskin, 2004; Karakulak vd., 2006; Keskin ve Oral, 2007; Türetken, 2009; Altın vd., 2015; Acarlı vd., 2018) olmasına karşın, gemi batığı yapay resiflerindeki tür çeşitliliğinin belirlenmesi üzerine bir çalışma bulunmamaktadır. Ayrıca, yöntem açısından literatürdeki bu çalışmalar incelendiğinde yalnızca bir tanesinde (Horasanll, 2016) yapay resiflerdeki tür çeşitliliğinin belirlenmesinde görsel sayım yöntemlerinin kullanıldığı dikkat çekmektedir. Horasanlı (2016) birey sayılarını aylık olarak en yüksek Mayıs ayında 1245 birey, en düşük değeri Haziran ayında 80 birey olarak bildirmiştir. Mevcut çalışmada en yüksek değer Mart ayında 4196 birey, en düşük değer Şubat ayında 291 birey olarak kaydedilmiştir. İki çalışmanın da Gökçeada'da gerçekleştirilmesine karşın oluşan farklılığın çalışmaların gerçekleştirildiği derinliklerin ve çalışma süresinin farklı olmasından dolayı kaynaklandığı düşünülmektedir.

Gemi batıkları yer değiştirmesi mümkün olmayan kültürel alanlar ve önemli yapay resif habitatları olarak hizmet sağlayan modern deniz tabanı özellikleridir (Walker vd., 2007). Gemi batıkları genç balık türlerinin sığınabilmesi için mükemmel bir yapay resif işlevi sunmaktadır (Krumholz ve Brennan, 2015). Gemi batıkları sayesinde oluşan bu resifler, yetişkin balık yayılımı ile yerel balıkçılığı artırabilir (Harmelin-Vivien vd., 2008; Forcada vd., 2009; Molloy vd., 2009). Stephan ve Lindquist (1989) eski ve yeni gemi batığı yapay resifleri ile balık cezbedici düzeneklerdeki balık topluluklarının karşılaştırmalı analizini yaptığı çalışmada eski gemi batığının en çok tür çeşitliliğine sahip olduğunu bildirmiştir. Bununla birlikte, yeni olan gemi batığında balık cezbedici düzeneklerden daha çok tür çeşitliliği gözlendiği de rapor edilmiştir. Mevcut çalışmada araştırılan gemi batığı yapay resifi henüz daha 3 yıllık bir batık olmasına rağmen çok sayıda tür çeşitliliğinin gözlenmiş olması önem taşımaktadır. Öte yandan, Brennan vd. (2016) tarihi gemi batıklarının bulunduğu alanların trol avcılığı nedeniyle büyük zarar gördüğünü belirtmiş ve trol avcılığının batıklardaki tarihi, bentik, ekolojik ve sediman doğasını yok ettiğini ifade etmiştir. Gemi batığı yapay resifler tür çeşitliliğinin zenginleşmesine, amatör, sportif ve hobi amaçlı balıkçılık faaliyetlerinin artmasına ve bölgesel düzeyde sosyo-ekonomik düzeyin geliştirilmesine imkan sağlamaktadır. Benzer şekilde, Brennan vd. (2016) yapay resifler olarak batık alanlarının korunmasının yerel balıkçılığı arttıracağı vurgulamıştır. Dolayısıyla, gemi batıklarının bulunduğu alanların korunması ticari ve sportif balıkçılığın gelişmesine katkılar sağlamaktadır. Ayrıca, ekosistem yaklaşımlı balıkçılık yönetiminin sağlanması ve uygulanması bağlamında da balıkçılık yönetimi uygulamalarında yönetici ve karar vericiler için potansiyel bir uygulama alanı sunmaktadır. Dolayısıyla, TCSG-132 gemi batığının denizel canlılar için önemli bir yapay resif işlevi görebilmesi için olumsuz etkileyecek faktörlerin engellenmesi ve mümkün olduğunca batığın korunması tür çeşitliliğindeki sürdürülebilirliğin sağlanması açısından elzem niteliktedir.

Gemi batığı çevresinde kalamar (Loligo vulgaris) türü 1 adet görünmesinin yanında bol miktarda kalamar yumurtaları da gözlenmiştir. Bu durum gemi batığı yapay resifinin de canlılar tarafından barınma, beslenme, korunma gibi amaçların yanında yumurtlama ve büyüme alanları olarak da kullanıldığını göstermektedir. Benzer şekilde, yapay resiflerin denizel canlılar tarafindan yaşamsal faaliyetlerini devam ettirebilecekleri birçok araştırmacı tarafından rapor edilmiştir (Acarli ve Ayaz, 2015; Acarl1 vd., 2019a; Acarlı vd., 2019b; Acarlı ve Kale, 2020a; Acarl1 ve Kale, 2020b). Bu 
çalışmada sadece kalamar türünün gemi batığı yapay resiflerini yumurtlama alanı olarak kullandığı tespit edilebilmiş olsa da diğer türlerin gemi batığı yapay resifinin çevresinde gözlenmesi diğer yaşamsal faaliyetlerin gerçekleştirildiğini net şekilde ortaya koymaktadır.

Francour vd. (1994) Akdeniz biyoçeşitlilik desenlerinin değişiklik gösterdiğini ve bu değişimin deniz suyu sıcaklı̆̆ındaki artış ile ilişkili olabileceğine işaret etmiştir. Benzer şekilde, Morri ve Bianchi (2001) Ligurya Denizi'ndeki çalışmaların da denizel biyoçeşitlilik ve iklim değişkenlikleri arasındaki ilişkiye dair örnekler sağladığını rapor etmiştir. Türk Boğazlar Sistemi aracılığıyla düşük sıcaklık ve tuzluluğa sahip besleyici element açısından zengin Karadeniz suları Ege Denizi'nin kuzeyine ulaşarak bu ortamdaki biyolojik çeşitliliği ve ekosistemi önemli ölçüde etkilemektedir. Gökçeada, bulunduğu konum itibariyle akıntı sistemlerinin de etkisi altında kalmaktadır (Kale, 2014). Gökçeada kıyılarındaki su sıcaklığı ve tuzluluğunun mevsimsel olarak değişkenlik sergilemesi, denizel biyoçeşitliliği de önemli derecede etkilemektedir (Gönülal, 2008). Acarli ve Ayaz (2015) sicaklık değişimleri ile tür sayıları değişimini değerlendirmiş ve paralellik belirlemiştir. Benzer şekilde, mevcut çalışmada da su sıcaklığındaki değişimler ile biyoçeşitlilik arasında bir ilişki olduğu düşünülmektedir.

Bianchi ve Morri (2000) Akdeniz biyoçeşitliliğinin iklim değişikliği ve insan etkileri altında hızlı bir değişim gösterdiğini, fakat hem ekosistemler hem de türler için koruma önlemlerinin halen zayıf olduğunu ifade etmiştir. Benzer şekilde, birçok çalışmada iklim değişikliğinin su kaynaklarını etkilediği rapor edilmiştir (Kale vd., 2016a; Kale vd., 2016b; Ejder vd., 2016a; Ejder vd.,2016b; Kale vd., 2018; Kale ve Sönmez, 2018a; Kale ve Sönmez, 2018b; Kale ve Sönmez, 2019a; Kale ve Sönmez, 2019b; Kale ve Sönmez, 2019c; Kale ve Acarlı, 2019a; Kale ve Acarlı, 2019b; Sönmez ve Kale, 2020). Ayrıca, Çanakkale ili için de iklim değişikliği nedeniyle sıcaklık (Kale, 2017a) ve buharlaşma (Kale, 2017b) eğilimlerinin değiştiği ve gelecekte daha çok artacağı tahmin edilmektedir. Dolayısıyla, bu bölgedeki denizel biyolojik çeşitliliğin iklim değişikliğinin olumsuz etkilerinden korunması biyoçeşitliliğin sürdürülebilirliğinin sağlanması açısından hayati önem taşımaktadır.

Sonuç olarak, Türkiye'de yapay resif çalışmaları yapılmasına karşın daha önce gemi batığı yapay resifi üzerinde ve çevresinde tür kompozisyonu belirlemeye yönelik bir çalışma bulunmamaktadır. $\mathrm{Bu}$ açıdan mevcut çalışma literatürdeki önemli bir boşluğun doldurulmasına katkı sağlamaktadır. İlerleyen zamanlarda gerçekleştirilecek yapay resif çalışmalarında farklı türlerin tespit edilmesi açısından fotokapan benzeri araçların kullanılması tür kompozisyonu belirlenmesine yönelik çalışmalarda önemli yararlar sağlayacaktır. Bu tarz çalışmalarda, balıkların gece beslenme davranışı gösterdikleri de göze alınarak gece dalışlarında gece görüşlü kameralar kullanılması durumunda tür kompozisyonunun belirlenmesine faydalı olacağı düşünülmektedir. Ayrıca, tür kompozisyonu hakkında daha fazla bilgi edinebilmek için gece ve gündüz saatlerinde uzatma ağları, fanyalı ağlar, alamana ağları, misina ağlar gibi av araçları kullanılması tavsiye edilmektedir. Diğer yandan, yapay resif çalışmalarında balıkların avlanma yöntemlerini ve hareket tarzlarını belirlemek amacıyla telemetrik sistemlerin kullanılması önerilmektedir. Gemi batığı yapay resiflerinin yaşı arttıkça daha çok tür cezbetmesinden dolayı diğer mevcut gemi batıklarının da tür çeşitliliği açısından karşılaştırmalı olarak araştırılması tavsiye edilmektedir.

Teşekkür: ÇOMÜ-3 isimli araştırma gemisinin kaptanı Yılmaz Tokoğlu'na lojistik destek sağladığı için teşekkür ederiz. Bu çalışma Sinan Kocabaş'ın yüksek lisans tezinin bir bölümünü içermektedir.

\section{KAYNAKLAR}

Acarl1, D., \& Ayaz, A. (2015). Using concrete artificial reef as a tool to enrich the new marine habitat in ErdekOcaklar Bay (Marmara Sea, Turkey). Fresenius Environmental Bulletin, 24(2A), 602-609.

Acarl1, D., \& Kale, S. (2020a). Species-specific artificial reef models for lobster (Homarus gammarus Linnaeus 1758). Ege Journal of Fisheries and Aquatic Sciences, 37(1), 1-7.

Acarl1, D., \& Kale, S. (2020b). Species composition of artificial reef models specifically designed for Homarus gammarus (Crustacea: Decapoda: Nephropidae) in the Sea of Marmara. Research in Marine Sciences, 5(1), 625-635.

Acarlı, D., Ayaz, A., Altinağaç, U., Özekinci, U., Bayhan, B., \& Kara, A. (2013). Determination of fish fauna at artificial reefs using underwater visual census methods in Erdek-Ocaklar (Marmara Sea/Turkey). In 10th CARAH - International Conference on Artificial Reefs and Related Aquatic Habitats, (pp 61). İzmir, Turkey. 
Acarlı, D., Kale, S., \& Çakır, K. (2018). A new maximum length for the garfish, Belone belone (Linnaeus, 1761) in the coast of Gökçeada Island (Aegean Sea, Turkey). Cahiers de Biologie Marine, 59(4), 385-389.

Acarlı, D., Kale, S., \& Kara, A. (2019a). New alternative fishing gear suggestions for trap fisheries from the waste recycle materials: Case study for Muricidae (Mollusca: Gastropoda). Marine Science and Technology Bulletin, 8(2), 92-97.

Acarl1, D., Kale, S., \& Kara, A. (2019b). Can brush parks aggregate species in lagoon systems? A case of Homa Lagoon, Aegean Sea, Turkey. Marine and Life Sciences, 1(1), 17-24.

Akça, N. (2010). Boncuk Koyu’ndaki (Gökova Körfezi) Carcharhinus plumbeus (Nardo, 1827) türünün biyoekolojisi üzerine sualtı gözlemleri. Adnan Menderes Üniversitesi, Fen Bilimleri Enstitüsü, Yüksek Lisans Tezi, Aydın.

Altın, A., Ayyıldız, H., Kale, S., \& Alver, C. (2015). Length-weight relationships of forty-nine fish species from shallow waters of Gökçeada Island, northern Aegean Sea Turkey. Turkish Journal of Zoology, 39(5), 971975.

Altinağaç, U., Ayaz, A., Acarli, D., \& Özekinci, U. (2013). Determination of the fish species composition of Saroz artificial reefs in İbrice (Saroz Bay, Turkey). 10th CARAH - International Conference on Artificial Reefs and Related Aquatic Habitats. İzmir, Turkey. 63 pp.

Ayaz, A., Ünal, V., Acarlı, D., \& Altınağac, U. (2010). Fishing gear losses in the Gökova Special Environmental Protection Area (SEPA), eastern Mediterranean, Turkey. Journal of Applied Ichthyology, 26(3), 416-419.

Bakır, A.K., Katağan, T., Aker, H.V., Özcan, T., Sezgin, M., Ateş, A.S., Koçak, C., \& Kırkım, F. (2014). The marine arthropods of Turkey. Turkish Journal of Zoology, 38(6), 765-831.

Bektaş, A. (2017). Gökçeada (Kuzey Ege denizi) çevresinde yaşayan sarpa [Sarpa salpa (Linnaeus, 1758)] balığl populasyonunun biyolojik özelliklerinin incelenmesi. Balıkesir Üniversitesi, Fen Bilimleri Enstitüsü, Yüksek Lisans Tezi, Balıkesir.

Bianchi, C.N., \& Morri, C. (2000). Marine biodiversity of the Mediterranean Sea: Situation, problems and prospects for future research. Marine Pollution Bulletin, 40(5), 367-376.

Bilecenoğlu, M., Kaya, M., Cihangir, B., \& Çiçek, E. (2014). An updated checklist of the marine fishes of Turkey. Turkish Journal of Zoology, 38(6), 901-929.

Bodilis, P., Louisy, P., Draman, M., Arceo, H.O., \& Francour, P., (2014). Can citizen science survey nonindigenous fish species in the eastern Mediterranean Sea?, Environmental management, 53(1), 172-180.

Brennan, M.L., Ballard, R.D., Roman, C., Bell, K.L.C., Buxton, B., Coleman, D.F., Inglis, G., Köyağasığlu, O., \& Turanl1, T. (2011). Evaluation of the modern submarine landscape off southwestern Turkey through the documentation of ancient shipwreck sites. Continental Shelf Research, 43, 55-70.

Brennan, M.L., Davis, D., Ballard, R.D., Trembenis, A.C., Vaughn, J.I., Krumholz, J.S., Delgado, J.P., Romon, C.N., Smart, C., Bell, K.L.C., Duman, M., \& DuVal, C. (2016). Quantification of bottom trawl fishing damage to ancient shipwreck sites. Marine Geology, 371, 82-88.

Bulleri, F., \& Airoldi, L. (2005). Artificial marine structures facilitate the spread of a non-indigenous green alga, Codium fragile ssp. tomentosoides, in the North Adriatic Sea, Journal of Applied Ecology, 42(6), 10631072 .

Cengiz, Ö., İşmen, A., Özekinci, U., \& Öztekin, A. (2011). Saroz Körfezi (Kuzey Ege Denizi) balık faunası üzerine bir araştırma. Afyon Kocatepe Üniversitesi Fen Bilimleri Dergisi, 11(011003), 31-37.

Cheung, W.W.L., Lam, V.W.Y., \& Pauly, D. (Eds). (2008) Modelling present and climate-shifted distribution of marine fishes and invertebrates. University of British Columbia, Fisheries Centre Research Report, 16(3), Vancouver.

Cochrane, S.K.J., Andersen, J.H., Berg, T., Blanchet, H., Borja, A., Carstensen, J., Elliott, M., Hummel, H., Niquil, N., \& Renaud, P.E. (2016). What is marine biodiversity? Towards common concepts and their implications for assessing biodiversity status. Frontiers in Marine Science, 3, 248.

Çoker, T., \& Akyol, O. (2018). Saroz Körfezi ve Gökçeada (Kuzey Ege Denizi) balık tür çeşitliliği üzerine bir değerlendirme. Turkish Journal of Maritime and Marine Sciences, 4(1), 81-92.

Ejder, T., Kale, S., Acar, S., Hisar, O., \& Mutlu, F. (2016a). Effects of climate change on annual streamflow of Kocabaş Stream (Çanakkale, Turkey). Journal of Scientific Research and Reports, 11(4), 1-11.

Ejder, T., Kale, S., Acar, S., Hisar, O., \& Mutlu, F. (2016b). Restricted effects of climate change on annual streamflow of Sarıçay stream (Çanakkale, Turkey). Marine Science and Technology Bulletin, 5(1), 7-11.

Forcada, A., Valle, C., Bonhomme, P., Criquet, G., Cadiou, G., Lenfant, P., \& Sanchez-Lizaso, J.L. (2009). Effects of habitat spillover from marine protected areas to artisanal fisheries. Marine Ecology Progress Series, 379, 197-211.

Francour, P., Boudouresque, C.F., Harmelin, J.G., Harmelin-Vivien, M.L., \& Quignard, J.P. (1994). Are the Mediterranean waters becoming warmer? Information from biological indicators. Marine Pollution Bulletin, 28(9), 523-526. 
Fricke, R., Eschmeyer, W.N., \& Van der Laan, R. (eds) (2020). Eschmeyer's catalog of fishes: Genera, species, references.(http://researcharchive.calacademy.org/research/ichthyology/catalog/fishcatmain.asp). Electronic version accessed 17 Jan 2020.

Genzano, G., Giberto, D., \& Bremec, C. (2011). Benthic survey of natural and artificial reefs off Mar del Plata, Argentina, southwestern Atlantic. Latin American Journal of Aquatic Research, 39(3), 553-566.

Gönülal, O. (2008). Gökçeada Kıyı Balıkçılığına Genel Bir Bakış. Gökçeada Değerleri Sempozyumu, Gökçeada, Çanakkale, Türkiye. ss. 151-133.

Gücü, A.C., \& Erkan, F. (2005). A holistic approach for the conservation of the Mediterranean monk seal on the Cilician coast of Turkey. Proceedings of the INOC International Workshop on Marine and Coastal Protected Areas, 23-25.

Gül, B., Lök, A, Ulaş, A., \& Düzbastılar, F.O. (2006). The investigation on fish composition at artificial reefs deployed on different substrates off Ürkmez Coast. Ege Journal of Fisheries and Aquatic Sciences, 23 (13), 431-434.

Gül, B., Lök, A., Özgül, A., Ulaş, A., Düzbastilar, F.O., \& Metin, C. (2011). Comparison of fish community structure on artificial reefs deployed at different depths on Turkish Aegean Sea coast. Brazilian Journal of Oceanography, 59, 27-32.

Harmelin-Vivien, M., Le Direach, L., Bayle-Sempere, J., Charbonnel, E., Garcia-Charton, J.A., Ody, D., PerezRuzafa, A., Renones, O., Sanchez-Jerez, P., \& Valle, C. (2008). Gradients of abundance and biomass across reserveboundaries in six Mediterranean marine protected areas: Evidence of fish spillover?. Biological Conservation, 141, 1829-1839.

Harmelin-Vivien, M.L., \& Harmelin, J.G. (1975). Pre'sentation d'une me'thode d'e'valuation "in situ" de la fauna ichtyologique, Travaux scientifiques du Parc national de Port-Cros, 1, 47-52.

Honario, P.P.F., Ramos, R.T.C., \& Feitoza, B.M. (2010). Composition and structure of reef fish communities in Parabia State, North-eastern Brazil. Journal of Fish Biology, 77, 907-926.

Hooper, D.U., Chapin, F.S.I., Ewel, J.J., Hector, A., Inchausti, P., Lavorel, S., Lawton, J.H., Lodge, D.M., Loreau, M., Naeem, S., Schmid, B., Setälä, H., Symstad, A.J., Vandermeer, J., \& Wardle, D.A. (2005). Effects of biodiversity on ecosystem functioning: a consensus of current knowledge. Ecological Monographs, 75(1), 3-35.

Horasanlı, A. (2016). Yıldız Koyu’nda (Gökçeada) bulunan balık topluluklarının dağılımlarının sualtı görsel sayım tekniği ile belirlenmesi. İstanbul Üniversitesi, Fen Bilimleri Enstitüsü, Yüksek Lisans Tezi, İstanbul.

Jensen, A.C. (2002). Artificial reefs of Europe: Perspective and future. ICES Journal of Marine Science, 59, 313.

Jimenez, C., Hadjioannou, L., Petrou, A., Andreou, V., \& Georojou, A. (2016). Fouling communities of two accidental artificial reefs (modern shipwrecks) in Cyprus (Levantine Sea). Water, 9(1), 11.

Kale, S. (2014). Gökçeada sı̆̆ sularında bulunan Sparidae ailesine ait genç balık türlerinin dă̆llımlarının CBS ile modellenmesi. Çanakkale Onsekiz Mart Üniversitesi, Fen Bilimleri Enstitüsü, Yüksek Lisans Tezi. Çanakkale.

Kale, S. (2017a) Climatic trends in the temperature of Çanakkale city, Turkey. Natural and Engineering Sciences, 2(3), 14-27.

Kale, S. (2017b) Analysis of climatic trends in evaporation for Çanakkale (Turkey). Middle East Journal of Science, 3(2), 69-82.

Kale, S., \& Acarlı, D. (2019a). Spatial and temporal change monitoring in water surface area of Atikhisar Reservoir (Çanakkale, Turkey) by using remote sensing and geographic information system techniques. Alinteri Journal of Agriculture Sciences, 34(1), 47-56.

Kale, S., \& Acarli, D. (2019b). Shoreline change monitoring in Atikhisar Reservoir by using remote sensing and geographic information system (GIS). Fresenius Environmental Bulletin, 28(5), 4329-4339.

Kale, S., \& Sönmez, A. Y. (2018b). Trend analysis of streamflow of Akkaya Stream (Turkey). In Dadaşoğlu, F., Tozlu, E., Çı̆̆, F. and Yıldırım, E (eds.). Proceedings of the 1st International Conference on Food, Agriculture and Animal Sciences, pp. 33-45. Antalya, Turkey.

Kale, S., \& Sönmez, A.Y. (2018a). Trend analysis of mean monthly, seasonally and annual streamflow of Daday Stream in Kastamonu, Turkey. Marine Science and Technology Bulletin, 7(2), 60-67.

Kale, S., \& Sönmez, A.Y. (2019a). Trend analysis for annual streamflow of Ilgaz Stream (Turkey). In Proceeding Book of the 2nd International Congress on Engineering and Life Science, pp. 631-639.

Kale, S., \& Sönmez, A.Y. (2019b). Trend analysis for annual streamflow of Araç Stream (Turkey). In Proceeding Book of the 2nd International Congress on Engineering and Life Science, pp. 706-713.

Kale, S., \& Sönmez, A.Y. (2019c). Trend Analysis for Streamflow of Devrekani Stream (Turkey). Review of Hydrobiology, 12(1-2), 23-37.

Kale, S., Altin, A., Ayyildiz, H., Özen, Ö.(2014a). Modeling the spatial distribution of juvenile striped sea bream (Lithognathus mormyrus Linnaeus, 1758) in relation to habitat structure in the shallow waters of 
Gökçeada using GIS. In Proceedings of the International Symposium on Fisheries and Aquatic Sciences: FABA 2014, (pp 126). Trabzon, Turkey.

Kale, S., Altin, A., Ayyildiz, H., Özen, Ö.(2014b). Modeling the habitat structure in the shallow waters of Gökçeada using GIS. In Proceedings of the International Symposium on Fisheries and Aquatic Sciences: FABA 2014, (pp 391). Trabzon, Turkey.

Kale, S., Altin, A., Ayyildiz, H., Özen, Ö.(2014c). Modeling the spatial distribution of juvenile annular sea bream (Diplodus annularis Linnaeus, 1758) in relation to habitat structure in the shallow waters of Gökçeada using GIS. In Proceedings of the International Symposium on Fisheries and Aquatic Sciences: FABA 2014, (pp 392). Trabzon, Turkey.

Kale, S., Altin, A., Ayyildiz, H., Özen, Ö.(2015a). Spatial distribution modelling of juvenile common pandora (Pagellus erythrinus Linnaeus, 1758) in relation to habitat in the shallow waters of Gökçeada using GIS. In Proceedings of the 7th International Conference on Information and Communication Technologies in Agriculture, Food and Environment (HAICTA 2015), (pp 672-680). Kavala, Greece.

Kale, S., Altin, A., Ayyildiz, H., Özen, Ö.(2015b). Spatial distribution and GIS modelling of juvenile garfish (Belone belone, Linnaeus, 1761) with regard to habitat in the shallow waters of Gökçeada Island (Northern Aegean Sea, Turkey). In Proceedings of the Turkish-Japanese Marine Forum-III International Workshop on Recent Developments in Marine \& Environmental Sciences, Sustainable Utilization of Water Resources, (pp 17). Çanakkale, Turkey.

Kale, S., Ejder, T., Hisar, O., \& Mutlu, F. (2016a). Climate change impacts on streamflow of Karamenderes River (Çanakkale, Turkey). Marine Science and Technology Bulletin, 5(2), 1-6.

Kale, S., Ejder, T., Hisar, O., \& Mutlu, F. (2016b). Effect of climate change on annual streamflow of Bakırçay River. Adiyaman University Journal of Science, 6(2), 156-176.

Kale, S., Hisar, O., Sönmez, A.Y., Mutlu, F., \& Filho, W.L. (2018) An assessment of the effects of climate change on annual streamflow in rivers in western Turkey. International Journal of Global Warming, 15(2), 190-211.

Karakulak, F.S., Erk, H., \& Bilgin, B. (2006). Length-weight relationships for 47 coastal fish species from the northern Aegean Sea, Turkey. Journal of Applied Ichthyology, 22(4), 274-278.

Keskin, Ç. (1996). Gökçeada civarı ihtiyofaunası'nın çeşitlilik ve verimlilik yönünden araştırılması. İstanbul Üniversitesi, Fen Bilimleri Enstitüsü, Yüksek Lisans Tezi, İstanbul.

Keskin, Ç. (2004). Composition of species and biomass of coastal fish around Gökçeada Island (NE Aegean Sea). Journal of Black Sea/Mediterranean Environment, 10, 187-200.

Keskin, Ç., \& Oral, M. (2007). A preliminary study on the fish community structure around Gökçeada Island, North Aegean Sea, Turkey. 38th CIESM (International Mediterranean Science Commusion) Congress, Istanbul, Turkey. Rapports et procès-verbaux des réunions Commission internationale pour l'exploration scientifique de la Mer Méditerranée, 38, 517.

Keskin, Ç., \& Ünsal, N. (1998). The fish fauna of Gökçeada Island, NE Aegean Sea, Turkey. Italian Journal of Zoology, 65, 299-302.

Kocabaş, S., \& Acarl1, D. (2019). First observation of loggerhead sea turtle Caretta caretta (Linnaeus 1758) around the shipwreck used as an artificial reef in the coasts of Gokceada Island, North Aegean Sea. Marine Science and Technology Bulletin, 8(2), 36-39.

Krumholz, J.S., \& Brennan, M.L. (2015). Fishing for common ground: Investigations of the impact of trawling on ancient shipwreck sites uncovers a potential for management synergy. Marine Policy, 31, 127-133.

Lök, A., \& Özgül, A. (2010). Fish assemblages around fish aggregation devices in Aegean Sea coast of Turkey. Rapports et procès-verbaux des réunions Commission internationale pour l'exploration scientifique de la Mer Méditerranée, 39, 573.

Lök, A., Gül, B., Ulaş, A., Düzbastılar, F.O., \& Metin, C. (2008). Diel variations on the fish assemblages at artificial reefs in two different environments of the Aegean Sea (Western coast of Turkey). Turkish Journal of Fisheries and Aquatic Sciences, 8, 79-85.

Lok, A., Gül, B., Ulaş, A., Metin, C., Düzbastılar, O., Çakaloz, A., \& Özgül, A. (2007). Determination of fish compositions at artificial reefs deployed three different depths $(20,30$ and 40m) in Aegean Sea coast of Turkey: Preliminary results. Rapports et procès-verbaux des réunions Commission internationale pour l'exploration scientifique de la Mer Méditerranée, 38, 531.

Lök, A., Metin, C., Ulaş, A., Düzbastilar, F.O., \& Tokaç, A. (2002). Artificial reefs in Turkey, ICES Journal of Marine Science, 59, 192-195.

Molloy, P.P., McLean, I.B., \& Cote, I.M. (2009). Effects of marine reserve age on fish populations: a global meta-analysis. Journal of Applied Ecology, 46(4), 743-751.

Morri C., \& Bianchi, C.N. (2001). Recent changes in biodiversity in the Ligurian Sea (NW Mediterranean): Is there a climatic forcing?. In: Faranda, F.M., Guglielmo, L., Spezie, G. (eds) Mediterranean Ecosystems. Springer, Milano. 
Özalp, H.B. (2009). Çanakkale Boğazı Çanakkale sualtı ve can kurtarma spor kulübü sualtı istasyonuna bırakılan fiberglas, ahşap, lastik, demir ve seramik malzemelerin cezbettiği balık türlerinin incelenmesi. Çanakkale Onsekiz Mart Üniversitesi, Fen Bilimleri Enstitüsü, Yüksek Lisans Tezi, Çanakkale.

Özgül, A., \& Lök, A. (2017). Artificial reef studies in Turkey. In: Erkanal, H., Şahoğlu, V., Tuğcu, İ. (Eds.), Proceedings of the 20th Annual Meeting of Underwater Science and Technology, İzmir, Turkey. Bilgin Kültür Sanat Yayınları, Ankara, Turkey

Öztürk, B., Doğan, A., Bitlis-Bakır, B., \& Salman, A. (2014). Marine molluscs of the Turkish coasts: an updated checklist. Turkish Journal of Zoology, 38(6), 832-879.

Roessig, J.M., Woodley, C.M., Cech, J.J., \& Hansen, L.J. (2004) Effects of global climate change on marine and estuarine fishes and fisheries. Reviews in Fish Biology and Fisheries, 14, 251-275.

Sakinan, S., \& Gucu, A.C., (2010). Selection of the priority areas on the west coasts of Mersin using GIS to assess a marine conservation planning. Rapports et procès-verbaux des réunions Commission internationale pour l'exploration scientifique de la Mer Méditerranée, 39, 793.

Sala, E., Kizilkaya, Z., Yildirim, D., \& Ballesteros, E. (2011). Alien marine fishes deplete algal biomass in the eastern Mediterranean. PLoS One, 6(2), e17356.

Sala, O.E., Chapin, F.S.3rd., Armesto, J.J., Berlow, E., Bloomfield, J., Dirzo, R., Huber-Sanwald, E., Huenneke, L.F., Jackson, R.B., Kinzig, A., Leemans, R., Lodge, D.M., Mooney, H.A., Oesterheld, M., Poff, N.L., Sykes, M.T., Walker, B.H., Walker, M., \& Wall, D.H. (2000). Global biodiversity scenarios for the year 2100. Science, 287(5459), 1779-1774.

Simon, T., Pinheiro, H.T., \& Joyeux, J.C. (2010). Target fishes on artificial reefs: Evidences of impacts over nearby natural environments. Science of the Total Environment, 409, 4579- 4584.

Sönmez, A. Y., \& Kale, S. (2020) Climate change effects on annual streamflow of Filyos River (Turkey). Journal of Water and Climate Change, (In press), doi:10.2166/wcc.2018.060

Stachowicz, J.J., Bruno, J.F., \& Duffy, E. (2002). Understanding the effects of marine biodiversity on communities and ecosystems. Annual Review of Ecology, Evolution, and Systematics, 38, 739-766.

Stephan, C.D., \& Lindquist, D.G. (1989). A comparative analysis of the fish assemblages associated with old and new shipwrecks and fish aggregating devices in Onslow Bay, North Carolina. Bulletin of Marine Science, 44(2), 698-717.

Türetken, K.F. (2009). Gökçeada civarı (Kuzey Ege Denizi) derin deniz balıklarının nitel-nicel özellikleri. İstanbul Üniversitesi, Fen Bilimleri Enstitüsü, Yüksek Lisans Tezi, İstanbul.

Ulaş, A., Düzbastılar, F.O., Lök, A., \& Metin, C. (2007). A pre-study for determining of efficiency of fish sampling methods on artificial reefs. Ege Journal Fisheries and Aquatic Sciences, 24 (3-4), 287-293.

Ulaş, A., Lök, A., Duzbastilar, F.O., Özgül, A., \& Metin, C. (2011). A new artificial reef design for octopus (Octopus vulgaris Cuvier, 1797) in the Aegean Sea and preliminary results. Brazilian Journal of Oceanography, 59, 21-25.

Walker, S., Schlacher, T., \& Schlacher-Hoenlinger, M. (2007). Spatial heterogeneity of epibenthos on artificial reefs: fouling communities in the early stages of colonization on an East Australian shipwreck. Marine Ecology, 28(4), 435-445.

Worm, B., Barbier, E.B., Beaumont, N., Duffy, J.E., Folke, C., Halpern, B.S., Jackson, J.B.C., Lotze, H.K., Micheli, F., Palumbi, S.R., Sala, E., Selkoe, K.A., Stachowicz, J.J., \& Watson, R. (2006). Impacts of biodiversity loss on ocean ecosystem services. Science, 314, 787-790.

Yıldız, T., Gönülal, O., \& Karakulak, S. (2012). Gökçeada (Ege Denizi) kıyı balıkçılığında kullanılan av araçları ve teknik özellikleri. Ístanbul Üniversitesi Su Ürünleri Dergisi, 27, 1-25. 